\title{
Estimação das elasticidades de substituição do comércio regional do Brasil
}

\author{
Weslem Rodrigues Faria* \\ Eduardo Amaral Haddad**
}

\begin{abstract}
Palavras-chave
elasticidades de Armington, comércio regional, estimação "model-consistent", economia brasileira.

\section{Classificação JEL}

C80, F14, R12.

\section{Keywords}

Armington elasticities, regional trade, modelconsistent estimation, Brazilian economy.
\end{abstract}

JEL Classification

C80, F14, R12.

\begin{abstract}
Resumo
O presente trabalho estima elasticidades de substituição do comércio regional do Brasil considerando 110 produtos e 558 microrregiões. As elasticidades foram estimadas com base no modelo de Armington (1969), adaptado de forma similar à sugestão de Bilgic (2002) quanto à definição das variáveis. Poucos trabalhos foram identificados na literatura que tiveram o objetivo de calcular elasticidades regionais de substituição no comércio. Isso pode estar relacionado ao fato de a geração do banco de dados ser não trivial, no sentido de requerer informações refinadas e bastante numerosas da economia. Os resultados das estimações apresentaram em geral coeficientes com sinais esperados, e as elasticidades variaram que acordo com os tipos de produtos. Produtos relacionados às atividades agrícolas e de extração tendem a apresentar coeficientes menos elásticos que os coeficientes das atividades de serviços. Os produtos industriais mostraram conjuntamente um coeficiente médio igual a -1,775.
\end{abstract}

\section{Abstract}

This study estimates elasticities of regional trade in Brazil considering 110 products and 558 regions. The elasticities were estimated using the Armington (1969) model, adapted from Bilgic's (2002) suggestion regarding the definition of variables. Few studies were identified in the literature that aimed at estimating elasticities of substitution in regional trade, adding relative importance to this study. This fact may be related to the generation of the database because of the non-triviality in the numerous requirements and specific information of the economy. The estimation results presented, in general, coefficients with expected signs and the elasticities change according to the types of products. Products related to agricultural and mining activities had less elastic coefficients than the coefficients of the service activities. The products related to industrial activities presented jointly an average coefficient equal to -1.775 .

\footnotetext{
*Professor adjunto da Faculdade de Economia da UFJF

**Professor titular do Departamento de Economia da FEA/USP
} 


\section{1_Introdução}

O comércio entre regiões funciona como forma de essas buscarem suprir suas demandas por produtos que, por algum motivo, não conseguem produzir. Muitos desses motivos estão ligados a restrições que podem se mostrar sob diversas maneiras, como, por exemplo, inexistência ou falta de dotação de fatores de produção, restrições físicas como fatores edafo-climáticos e de ordem ambiental, infraestrutura incipiente para desenvolvimento de atividades produtivas, mas principalmente em razão da escala econômica de mercado, o que inviabiliza a consolidação de investimentos. As regiões, dado esse contexto, demandam produtos diversos, e mesmo as regiões com maiores níveis de atividade econômica não conseguem produzir todos os bens de que necessitam, não apenas para suprir demanda de consumidores finais, mas também com relação a insumos para produção. $\mathrm{O}$ comércio mostra-se uma alternativa viável para resolver tais questões, de modo que um sistema de comércio pode ser configurado englobando várias regiões em um contexto econômico integrado.

A existência do comércio entre regiões suscita outras questões. Uma delas refere-se aos tipos de atividades produtivas desempenhadas por cada região. Uma visualização completa desde cenário pode indicar, mesmo que de forma exploratória, como os fluxos de comércio podem ocorrer de um local para o outro, considerando basicamente escala de mercado e distância física. Outro fato que pode ser analisado dessa visualização refere-se à identificação das regiões mais propensas ao comércio. Isso está diretamente relacionado ao grau de dependência do comércio: regiões que possuem produção mais especializada tendem a necessitar de mais produtos de outras regiões. Além disso, há a questão demo-espacial, uma vez que regiões cuja população se encontra mais dispersamente distribuída no espaço tendem a produzir bens principalmente para consumo próprio.
Levando em conta o sistema econômico de forma ampla e integrada, a configuração das principais linhas de "desejo" do comércio pode ser demarcada, emergindo como consequência a forma com que a interdependência ocorre mais fortemente no espaço.

Não obstante, a interdependência no comércio leva à tona um aspecto importante, isto é, o grau de comercialização dos bens da economia. Essas duas questões não são independentes, já que a vocação regional para a produção fornece indícios acerca da sua necessidade de realização de comércio. Neste contexto, o presente trabalho tem como objetivo discutir questões relacionadas à dependência no comércio inter-regional de produtos considerando o espaço da economia brasileira como referência, por meio da identificação do grau de sensibilidade dos produtos ao comércio. Para isso, são estimadas elasticidades de comércio inter-regional ou elasticidades regionais de Armington do comércio dos 110 produtos especificados de acordo com o Novo Sistema de Contas Nacionais do IBGE. A escala regional utilizada é a microrregião homogênea, o que permitiu análise mais consistente do comércio por considerar um número amplo de regiões e, com isso, uma quantidade maior de informações fornecendo mais riqueza aos resultados obtidos.

Vale destacar que, na literatura, esse tipo de abordagem é escasso, e poucos trabalhos tiveram como objetivo retratar estimações de elasticidades de comércio inter-regional. A maioria dos trabalhos se preocupa em estimar relações de comércio entre bens domésticos (nacionais) e importados de outros países, o que é importante também, uma vez que permite a identificação dos produtos nacionais com maior vocação para exportação e os produtos mais necessários (e dependentes) em termos de importação. Isso suscita, como na análise para o comércio inter-regional 
mencionada, o grau de dependência do mercado externo aos produtos nacionais e vice-versa. Por exemplo, o fato de alguns produtos terem coeficientes mais elásticos demonstraria a existência de menos dependência com relação ao comércio desses produtos.

Desde o trabalho de Armington (1969) - que derivou coeficientes para o cálculo das elasticidades de comércio, com aplicação em procedimentos econométricos de estimação -, muitos trabalhos foram realizados para aplicação empírica, focados no comércio entre bens domésticos e importados. Dada a vasta extensão de aplicações na literatura, tais trabalhos não serão analisados aqui, uma vez que o presente trabalho foca na estimação de elasticidades de comércio inter-regional, mas informações adicionais podem ser encontradas, por exemplo, em Shiells et al. (1986), Reinert e Roland-Holst (1992), Shiells e Reinert (1993), Blonigen e Wilson (1999) e Gallaway et al. (2003).

Por outro lado, foi possível identificar apenas alguns trabalhos empenhados na estimação de elasticidades de substituição no comércio inter-regional, isto é, entre regiões dentro de um mesmo contexto econômico, e não no comércio entre bens domésticos e importados. Os trabalhos mencionados a seguir são importantes, embora sem entrar em muitos detalhes, pois, além de serem relativamente escassos, alguns apresentam abordagens alternativas em relação à análise de comércio entre produtos domésticos e importados. Tais trabalhos tiveram seus resultados analisados comparativamente aos encontrados neste estudo, contribuindo para uma análise qualitativa mais robusta e validação deles. Primeiramente, tem-se a publicação de Tooze (1976), que se configurou de forma bastante seminal, sendo uma contribuição quase contemporânea ao estudo de Armington (1969). Aquele trabalho dedicou atenção na estimação de elasticidades regionais para 14 setores industriais dentro do Reino Unido. Utilizou duas abordagens pa- ra estimar as elasticidades de substituição regional: ambas com base em uma função de produção, todavia uma com a hipótese de retornos constantes de escala e a outra sem essa hipótese.

Outro trabalho encontrado é o de Bilgic et al.(2002), que atentaram para a estimação de elasticidades de substituição regional no comércio de produtos dos Estados Unidos. Esse trabalho foi utilizado neste estudo por causa principalmente da forma com que definiu algumas variáveis, fornecendo uma interpretação com potencial de aplicação alternativa para a avaliação do comércio inter-regional. Uma preocupação deste estudo foi a realização da comparação das estimativas das elasticidades de comércio regional encontradas com as elasticidades encontradas em outros estudos para o comércio entre bens domésticos e importados. Em certo sentido, essa comparação é válida, dada a escassez de trabalhos que buscaram estimar as elasticidades regionais e a necessidade de validação dos resultados. Por fim, Turner $e t$ al. (2012) estimaram elasticidades de substituição no comércio regional entre o Estado de Illinois e os demais Estados dos Estados Unidos. Neste caso, o comércio regional era restrito no sentido de apenas captar fluxos bidirecionais entre uma região com as outras, sem contar com a interdependência entre o conjunto completo de regiões.

Outros três trabalhos podem ser citados que estimaram elasticidades de comércio regional utilizando dados da economia brasileira: Haddad (2004) desenvolveu um método de estimação consistente com a estrutura de um banco de dados interestadual para o Brasil (model-consistent estimation procedure), posteriormente aplicado, conjuntamente, nos trabalhos de Faria (2009) e Magalhães (2009). As estimativas geradas foram produzidas dentro de pesquisas que envolviam análises utilizando modelos de equilíbrio geral computável (EGC). Em alguns casos, ocorreram alguns problemas com relação às estimativas, e os coeficien- 
tes de alguns setores mostraram-se não significativos e com sinal não esperado. Dado esse problema, a calibragem dos modelos com as elasticidades exigiu a adoção de hipóteses ad hoc sobre alguns valores para os produtos que apresentaram problema.

Em razão dessas considerações, o presente trabalho foi dividido da forma que se segue: além desta introdução, outras quatro seções foram desenvolvidas. A próxima seção descreve o banco de dados, detalhando os procedimentos adotados na criação de cada variável utilizada no estudo. Esse é um dos pontos de maior diferencial do trabalho ao deixar claro que a implementação da geração das estimativas das elasticidades de comércio regional é não trivial por: i) exigir gama muito grande de informações traduzidas em dados muito específicos da economia, a níveis elevados de desagregação espacial e por tipo de produção; e ii) meios técnicos para implementação e consolidação dos dados. A seção 3 descreve o procedimento de estimação das elasticidades comércio, desenvolvendo de forma simples e clara a equação básica a ser estimada. A seção 4 analisa os resultados encontrados e busca compará-los com aqueles já existentes na literatura. A última seção tece algumas considerações finais.

\section{2_Dados}

Os dados utilizados no procedimento de estimação das elasticidades correspondem a informações obtidas, em parte, no âmbito do estudo do Plano Nacional de Logística e Transporte (PNLT). Tais informações referem-se ao ano de 2007 e são desagregadas nos 110 produtos do Novo Sistema de Contas Nacionais (NSCN) do IBGE. A cobertura espacial abrange as 558 microrregiões brasileiras. O Quadro 1 resume as variáveis utilizadas, bem como apresenta breve descrição e as principais fontes utilizadas para a sua obtenção.
Quadro 1_Variáveis utilizadas

\begin{tabular}{l|r|l} 
Variável & Descrição & Fonte \\
\hline$Q$ & $\begin{array}{r}\text { Medida de comércio } \\
\text { inter-regional }\end{array}$ & Dados da pesquisa \\
\hline Custo & $\begin{array}{r}\text { Medida de custo de transfe- } \\
\text { rência inter-regional }\end{array}$ & Dados da pesquisa \\
\hline PIB & Produto Interno Bruto & \\
\hline Densidade & $\ldots$ População/área & $\ldots$ \\
\hline IpeaData
\end{tabular}

A variável $Q$ é uma proxy para o nível do fluxo de comércio entre as regiões no território brasileiro e corresponde à razão entre o total comprado por uma região $r$ de uma região $s$ (incluindo $r=s$ ) e o total de compras da região r. A variável Custo é uma medida de custo de transação inter-regional e refere-se ao preço relativo entre as regiões $s$ e $r$, medido pelo custo de transferência entre os pares regionais, do ponto de vista da região compradora. A variável PIB representa o Produto Interno Bruto municipal agregado por microrregião e corresponde ao PIB da região de origem do fluxo de comércio. A variável Densidade representa a densidade da região de destino das vendas, funcionando como medida relativa entre o fluxo de comércio e o tamanho do mercado consumidor.

\section{1_Medida de comércio inter-regional $(Q)$}

A variável $Q$ foi construída seguindo algumas etapas de trabalho que serão ser descritas abaixo, de forma detalhada, tendo em vista o fato de que esta etapa foi uma das mais importantes no processo de estimação das elasticidades. Inicialmente, o PIB nacional foi desagregado nos vetores dos componentes da demanda final (consumo das famílias, investimento, gastos do governo, exportações e importações) por Estado (UF); em seguida, esses mesmos componentes 
foram desagregados por microrregião de forma consistente com os resultados estaduais. Como as informações dessa identidade não estão disponíveis em fontes oficiais, procedimentos foram realizados individualmente para a obtenção de cada variável. Em um contexto geral sobre elas, utilizaram-se proporções calculadas valendo-se de fontes oficiais ou de pesquisas específicas para desagregar cada identidade em nível de Estado ou microrregião.

Essa etapa utilizou de forma intensiva diversas fontes de dados. Em âmbito estadual, o PIB corresponde ao Produto Interno Bruto a preços de mercado das Contas Regionais do Brasil; o Consumo do Governo, à estrutura do PIB da administração pública; e o Investimento, à estrutura do PIB da construção civil, informações essas também obtidas das Contas Regionais. O Consumo das Famílias foi desagregado com base em informações estruturais da Pesquisa de Orçamentos Familiares (POF) referente aos anos 2008-2009. Com o objetivo de avaliar a consistência dos dados, foi realizado um procedimento de análise de correlação entre as informações da despesa familiar da POF e as do rendimento do trabalho da Pesquisa Nacional por Amostra de Domicílios (PNAD) de 2008. O resultado da Figura A.1 do Anexo mostra correlação acentuada entre essas. As informações referentes às relações de compra e venda dos Estados com o exterior foram obtidas no sítio eletrônico do Ministério do Desenvolvimento, Indústria e Comércio Exterior compilados no Sistema ALICEWEB.

Para a obtenção dos dados microrregionais, a estratégia geral foi usar as informações das contas estaduais e desagregá-las empregando a participação percentual (shares) microrregional dessas identidades. Isso se justifica porque as fontes de informações são distintas para a construção dessas contas em decorrência de que, para as contas estaduais, há disponibilidade de informações de melhor qualidade, como aquelas da PNAD e da POF, do que as informações disponíveis em nível microrregional. Por exemplo, para a elaboração da conta "Consumo das Famílias" em âmbito estadual, foram utilizadas as informações da POF, ao passo que, para as contas microrregionais, foram usadas as informações de rendimento total da RAIS para cálculo das shares. A obtenção da participação percentual microrregional foi alcançada desagregando o total estadual da conta pelas suas microrregiões. De posse dessas shares, desagregou-se posteriormente a conta estadual pelas microrregiões. As contas microrregionais foram obtidas baseando-se na aplicação da participação percentual (shares) das microrregiões sobre a soma do respectivo Estado.

A geração dos dados microrregionais de PIB teve como base as informações de PIB municipal compiladas pelo IBGE, agregadas para microrregião. Para o Consumo das Famílias, foram utilizadas shares obtidas com informações de rendimento da RAIS; tais informações apresentaram mais de 0,99 de correlação com os dados de consumo da POF, o que forneceu credibilidade para uso daquela base. Os valores construídos para o investimento microrregional tiveram como base o PIB da construção civil disponibilizado pelo IBGE e para o Consumo do Governo das microrregiões foi utilizado o PIB da administração pública obtido das Contas Municipais. Com relação às Exportações e Importações, os dados de referência foram às informações da balança comercial municipal, consolidadas pelo Ministério do Desenvolvimento, Indústria e Comércio Exterior. Vale destacar que os dados das diversas fontes serviram como base para a construção de participações, que foram utilizadas como referência para desagregação dos dados estaduais. Estes, por sua vez, são consistentes com as informações para o Brasil consolidadas pelas Contas Nacionais. Assim, obtiveram-se os dados microrregionais do PIB e dos seus componentes em níveis estadual e microrregional, mantendo-se a consistência sistêmica. Além de 
transações com o exterior, as microrregiões fazem comércio com outras microrregiões. Ao final dessa etapa, tal comércio pode ser quantificado por resíduo da relação entre o PIB microrregional e os outros componentes das contas microrregionais.

A âncora mencionada anteriormente refere-se à informação sobre o PIB e seus componentes, que corresponde aos dados da Tabela de Recursos e Usos do ano de 2007 para o Brasil, publicada pelo IBGE. Dessa forma, esses dados forneceram o referencial necessário para a manutenção da consistência no processo de desagregações setorial e espacial subsequentes.

A etapa seguinte consistiu na regionalização da produção dos 110 produtos especificados de acordo com o NSCN em nível microrregional. Para isso, foram utilizadas duas fontes de informações: i) matriz de origem-destino (O-D) do Plano Nacional de Logística e Transporte (PNLT) de 2007, que apresenta estimativas do fluxo de carga inter-regional, em toneladas; e ii) banco de dados da RAIS como fonte complementar de dados microrregionais, tendo como referência as informações de emprego setorial da divisão de Grupos da Classificação Nacional das Atividades Econômicas versão 2.0 (CNAE 2.0). Com relação a este segundo item, um procedimento adicional foi implementado para compatibilização das categorias da CNAE com os produtos das Contas Nacionais, tomando como base a correspondência entre as duas nomenclaturas (ver Tabelas A.1 e A.2 do Anexo).

$\mathrm{O}$ valor da produção é relativo à produção das atividades contida na Tabela de Recursos de Bens e Serviços do ano de 2007, disponibilizada pelo IBGE para o fluxo entre os 110 produtos e os 56 setores. Tais dados funcionaram como âncora para a obtenção da produção desagregada por microrregião. Algumas decisões tiveram que ser tomadas na escolha da fonte a ser utilizada para a desagregação microrregional da produção, com base em alguns critérios.
Os produtos foram divididos em cinco grupos, de acordo com as características especificas de cada um, com abrangência ampla para que todos obtivessem cobertura. O Quadro 2 apresenta a descrição dos grupos dos produtos.

As decisões de escolha da fonte de informação para desagregação da produção foram tomadas considerando análises detalhadas para cada produto para detectar a existência de inconsistência nos dados. Um procedimento rigoroso de validação das informações foi empregado, e, para isso, dados alternativos foram criados para testar a robustez sistêmica da base de dados. Assim, uma segunda fonte de dados foi estabelecida com base no banco de dados da RAIS para verificar as possíveis discrepâncias com relação às informações obtidas por meio da matriz de origem-destino. O cruzamento dessas informações permitiu a visualização das diferenças entre as duas fontes, fornecendo maior grau de liberdade no processo de escolha. Foram construídos mapas da distribuição espacial dos produtos como subsídio para a verificação dos dados de cada fonte, o que auxiliou de forma mais contundente o processo de escolha.

O passo seguinte consistiu na desagregação nacional das exportações dos produtos para microrregião. Isso foi feito com base em dois grupos de informações: i) exportações em nível estadual, de acordo com a classificação CNAE 2.0; e ii) dados da matriz de origem-destino da produção voltada para o mercado externo dos produtos. $\mathrm{O}$ primeiro conjunto de dados teve a necessidade de ser obtido pelo fato de a matriz de origem-destino não contemplar todos os produtos. Tal conjunto de dados foi trabalhado previamente para que a desagregação por microrregião fosse implementada. O trabalho consistiu na conversão dos fluxos de exportação da classificação da CNAE para a classificação de produto em concordância com as Contas Nacionais, procedimento esse análogo ao realizado e descrito anteriormente para a desagregação da produção. De 
Quadro 2_Descrição dos grupos dos produtos

\begin{tabular}{|c|c|}
\hline Grupo & Descrição \\
\hline 1 & $\begin{array}{l}\text { Produtos elencados por valor bruto de produção pela } \\
\text { modelagem econômica adotada, com possibilidade de ela- } \\
\text { boração de matriz O-D pelo critério de planejamento de } \\
\text { transporte regional de carga, tais como: complexo soja, } \\
\text { milho, siderúrgicos, combustíveis, etc. }\end{array}$ \\
\hline 2 & $\begin{array}{l}\text { Produtos elencados pelo critério de valor bruto de } \\
\text { produção segundo modelagem econômica adotada, com } \\
\text { possibilidade de dimensionamento da produção, mas sem } \\
\text { precisão para elaboração de matriz O-D pelo critério de } \\
\text { planejamento de transporte regional de carga, em fun- } \\
\text { ção da dispersão dos locais de consumo desses produtos } \\
\text { e pela carência de bases de dados, tais como leite, café, } \\
\text { farinha de trigo, etc. }\end{array}$ \\
\hline $4^{a}$ & $\begin{array}{l}\text { Produtos elencados pelo critério de valor bruto de } \\
\text { produção pela modelagem econômica adotada, com } \\
\text { grande dispersão de produção e/ou consumo, não } \\
\text { permitindo análises setoriais e com alto valor agregado. }\end{array}$ \\
\hline $4 b$ & $\begin{array}{l}\text { Produtos elencados pelo critério de valor bruto de } \\
\text { produção pela modelagem econômica adotada, com } \\
\text { grande dispersão de produção e/ou consumo, não } \\
\text { permitindo análises setoriais e com médio valor agregado. }\end{array}$ \\
\hline 5 & $\begin{array}{l}\text { Constituído por produtos elencados pelo critério de valor, } \\
\text { mas que não demandam transporte, tais como eletricidade, } \\
\text { intermediação financeira, aluguel de imóveis, etc. }\end{array}$ \\
\hline
\end{tabular}

posse das informações de exportação por Estado (UF) para os produtos, a etapa seguinte consistiu na desagregação por microrregião desses fluxos. Os dados de exportação da matriz de origem-destino também foram compilados por Estados, de modo que a conjunção desses dois grupos de informações fornecesse o cenário completo das exportações dos produtos e por Unidade da Federação. A partir disso, participações foram criadas em relação ao total exportado por Estado e utilizadas para computar os dados de exportação por produto das Contas Nacionais do IBGE.
Para a desagregação consistente dessas informações por microrregião, extrapolou-se a mesma relação Exportações/VBP do Estado para suas microrregiões, de modo que as exportações por produto e por microrregião fossem obtidas de forma consistente com as informações das Contas Nacionais. Antes da desagregação para microrregião, alguns procedimentos de ajuste foram feitos para corrigir problemas de inconsistência relacionados à existência de relações Exportações/VBP maiores do que um. Tal problema surgiu em poucos casos, graças à tendência que pode ser observada nos dados com relação à concentração das atividades exportadoras em alguns Estados.

De posse do VBP e das exportações por produto e por microrregião, o passo seguinte representou a geração das demandas por produtos domésticas e por produtos importados para cada microrregião. A geração de ambas as demandas utilizou uma informação comum, ou seja, a produção setorial das microrregiões, obtida com base na produção por produtos das microrregiões. Para encontrar tal informação, foi realizado um procedimento de agregação padrão: a partir da multiplicação da matriz de produção normalizada de 2007, cuja dimensão é setor $\times$ produto, isto é, $56 \times 110$, pela matriz de VBP de dimensão produto $\times$ microrregião, ou seja, $110 \times 558$, obteve-se uma matriz de VBP com dimensão setor $\times$ microrregião ou $56 \times 558$. Além disso, a estimação da demanda doméstica utilizou a estrutura da Matriz de Usos e Recursos de 2007. Foram construídos coeficientes de uso relativos ao valor da produção setorial e dos componentes da Absorção Doméstica (Consumo das Famílias, Investimento e Gastos do Governo para cada produto, fornecendo uma matriz 59 ( 56 setores mais os três componentes da Absorção Doméstica) ×110. Para a estimação da demanda por produtos importados, o procedimento realizado foi análogo, porém a matriz de coeficientes foi gerada valendo-se da Matriz de Importações, e não da Matriz de Usos e Recursos de produtos domésticos. 
A estimação da demanda doméstica, portanto, fez uso de duas informações: i) dos níveis da produção por setor e dos componentes da Absorção Doméstica por microrregião; e ii) da matriz de coeficientes de uso gerada com base na Matriz de Usos e Recursos. Vale destacar que a matriz de coeficientes utilizada foi a mesma para todas as microrregiões; o que difere entre as microrregiões para o cálculo da demanda foi seu vetor de VBP setorial e Absorção Doméstica correspondente.

A geração da demanda doméstica seguiu o seguinte procedimento: para cada microrregião, o VBP setorial e os componentes da Absorção Doméstica foram distribuídos de acordo com os valores da matriz de coeficientes. Cada microrregião tem um vetor de produção setorial e Absorção Doméstica correspondente na matriz de VBP e Absorção Doméstica. Assim, a demanda associada a cada vetor microrregional foi estimada distribuindo-se os níveis de produção setorial, Consumo das Famílias, Investimento e Gastos do Governo, de acordo com as informações dos coeficientes de uso de produtos correspondentes. A agregação dos resultados forneceu um vetor de demanda doméstica por produto por microrregião. Agrupando os 558 vetores de demanda por produto, obteve-se a matriz de demanda doméstica por produtos. O procedimento para estimação da demanda por produtos importados foi análogo, mudando apenas a matriz de coeficientes a ser utilizada, sendo a Matriz de Importação o conjunto de informações relevantes. Assim, como na estimação da demanda doméstica, todas as microrregiões utilizam a mesma matriz de coeficientes (nacional).

Essas demandas estimadas, entretanto, não apresentam os valores "corretos", uma vez que não foi garantida a consistência com as informações das Contas Nacionais. Tais demandas forneceram a estrutura necessária para que os valores de interesse fossem distribuídos. Com relação à demanda por produtos domésticos, os seus valores por produto devem ser consistentes com os valores por produto da oferta doméstica, para que seja mantida a consistência no mercado de bens da economia. A matriz de oferta de bens domésticos foi calculada pela diferença, elemento a elemento, entre a matriz de VBP e a matriz de exportações. Assim, obteve-se toda a produção nacional que não foi exportada, portanto ofertada domesticamente. Tendo por base a matriz de demanda estimada, foram construídos vetores de participação relativos a cada produto, que, multiplicados com o total do produto ofertado domesticamente, forneceu de forma consistente a demanda doméstica por produto. Para a demanda por produtos importados, o procedimento foi mais simples: foram construídos vetores de participação por produto com base na matriz de demanda estimada, cujos coeficientes foram utilizados para distribuir os valores das importações dos produtos das Contas Nacionais. Dessa forma, o equilíbrio foi também mantido entre a oferta e a demanda por produtos importados.

Com essas informações desagregadas por microrregião e por produto, ou seja, VBP, exportações, demanda por bens domésticos e demanda por bens importados, outros indicadores puderam ser calculados, apesar de não serem usados nas etapas subsequentes. O saldo doméstico para cada microrregião foi calculado pela diferença entre a oferta e a demanda doméstica por cada produto. Isso permite, por exemplo, detectar as regiões que são mais ou menos dependentes de produtos de outras regiões domésticas. $\mathrm{O}$ saldo externo foi calculado pela diferença entre as exportações e as importações microrregionais para cada produto. Esse indicador poderia sugerir as regiões com maior vocação para exportar e para importar. Por fim, o saldo total, calculado pela soma do saldo doméstico e do saldo externo, poderia indicar as microrregiões exportadoras ou importadoras líquidas.

De posse desse banco de dados amplo e consistente, em termos de desagregação espacial e de nível de atividade 
econômica, foi possível gerar matrizes de fluxos de comércio para os produtos entre as microrregiões brasileiras. Essa etapa representou um ponto-chave na trajetória de geração das informações, sendo compreendida amplamente pela aplicação de esforço computável, ao invés de pesquisa por dados e escolhas feitas com base em critérios específcos. O procedimento consistiu da imputação de três informações: i) demanda por bens domésticos por produto e por microrregião; ii) oferta doméstica de bens por produto e por microrregião e; iii) matriz de impedância representada pela distância mínima pela rede de transporte em quilômetros entre as sedes das "capitais" microrregionais dos pares de regiões de origem e regiões de destino.

A matriz de impedância funcionou como restrição ao sistema, fornecendo a proxy necessária para direcionar a forma com que o comércio se estabelece no cenário econômico-espacial do Brasil. Tal matriz foi gerada no âmbito do estudo do PNLT de 2007 e compreende a conexão entre todas as microrregiões brasileiras. Neste estudo, três tipos de indicadores foram gerados para a determinação do fluxo de comércio inter-regional, compreendendo pares de origem-destino: i) fluxo de custo mínimo em R \$/tonelada; ii) tempo mínimo de viagem em horas e; iii) distância mínima em quilômetros.

Para a geração do fluxo de comércio, a terceira opção foi escolhida por representar de forma mais generalizada a restrição sistêmica para os produtos. A maneira pela qual o fluxo de comércio inter-regional foi calculado neste estudo exigia que apenas uma matriz de impedância fosse utilizada, independentemente das características de cada produto. Um procedimento adicional teve de ser realizado para que a matriz de distância fosse consolidada. Não havia, nas matrizes de origem-destino do PNLT, alguns fluxos de comércio entre pares de microrregiões. Isso era indicativo de que o comércio entre tais microrregiões não existia ou era quase desprezível. Dessa forma, estabeleceu-se uma distância ad hoc muito grande entre tais microrregiões para representar esse fato, impondo restrição na geração de fluxo de comércio entre elas.

O cálculo dos fluxos de comércio para os produtos utilizou um procedimento apresentado por Dixon e Rimmer (2004) para a obtenção das chamadas Shin tables. ${ }^{1}$ A geração das tabelas pode ser descrita basicamente em três etapas. Na primeira etapa, são criadas 110 tabelas, correspondentes a cada um dos produtos, com dimensão $558 \times 558$. Em outras palavras, nesta etapa são geradas 110 matrizes para representar o fluxo entre as microrregiões do Brasil, sendo que, em tais matrizes, as linhas representam as regiões de origem ou vendedoras, e as colunas, as regiões de destino ou comparadoras.

A segunda etapa envolveu o cálculo das informações para preenchimento das matrizes dos produtos. Esta etapa envolve a utilização das três informações citadas anteriormente, demanda por bens domésticos, oferta doméstica e distância (que já inclui as restrições dadas pelas matrizes O-D). Além disso, outra informação necessária foi a determinação de um fator de apropriação regional inicial representado por um coeficiente associado a cada produto. Tal fator foi utilizado para informar ao processo de cálculo o nível de comercialização de cada produto, isto é, para determinar se um produto é muito ou pouco comercializável. $\mathrm{O}$ fator variou de 0,5 a 1, sendo que, quanto menos comercializável é o produto, mais próximo de 1 é seu coeficiente. Foi imputado valor igual 0,5 para os produtos 1 ao 90 e 0,9 aos demais. Nesta etapa, os valores calculados são estimativas preliminares que preenchem as matrizes. Inicialmente, os valores da diagonal principal das matrizes são preenchidos considerando o fato de o produto ser ou não muito comercializável; em seguida, as informações fora da diagonal são preenchidos, levando em conta o mesmo fato e a distância entre os pares de origem-destino. 
A última etapa consistiu no balanceamento das informações geradas na segunda etapa. Para isso, foram utilizados os dados de demanda e oferta doméstica originais. Tal balanceamento é feito para garantir que haja consistência sistêmica, isto é, que os valores dos fluxos de comércio gerados sejam consistentes com os totais dos valores imputados. Isso foi feito por meio do método RAS. A implementação desse método necessita de duas informações: (i) os valores de equilíbrio da situação inicial; e (ii) os valores alvo. Tais valores alvo são os valores que se tem inicialmente e que se busca obter como valor total nos fluxos das linhas e nos fluxos das colunas.

Neste trabalho, as matrizes com as estimativas iniciais dos fluxos de comércio obtidas na segunda etapa representam os valores da situação inicial, e os vetores de demanda e oferta doméstica representam os valores alvo. Os vetores de demanda e oferta doméstica por produto correspondem à soma ao longo dos produtos; portanto, são vetores em que é representado o total dos produtos para todas as microrregiões. Assim, o método RAS caracteriza-se por um procedimento iterativo, e, neste trabalho, a implementação funcionou da seguinte forma: os valores iniciais dados pela segunda etapa foram calculados iterativamente considerando as informações de todo o sistema, até que se alcançasse a convergência para um resultado consistente com os valores dos vetores de demanda e oferta domésticas originais.

Ao final de todas essas etapas, foram obtidos os fluxos de comércio entre as microrregiões para os produtos. Com isso, todas as informações necessárias para a construção da variável $Q$ utilizada para estimar as elasticidades regionais encontravam-se disponíveis. No entanto, alguns procedimentos tiveram de ser realizados para que sua implementação fosse possibilitada. Inicialmente, para cada produto e com base nas matrizes de fluxos de comércio entre as microrregiões, foi calculada a proporção do fluxo do produto de cada par de origem-destino em relação ao total do fluxo de compra, isto é, do total da coluna. Assim, para cada produto, foi construída uma matriz $558 \times 558$ de participação do fluxo em relação ao total da coluna. Em seguida, as colunas das matrizes foram empilhadas, fornecendo um total de 311.364 ( 558 multiplicado por 558) informações por produtos. Por fim, a variável $Q$ foi estabelecida após o agrupamento dessas colunas de todos os produtos.

\section{2_Medida de custo de transferência inter-regional}

A variável Custo, que mede o custo de transferência inter-regional, foi obtida após a consolidação de uma informação mencionada anteriormente relativa aos indicadores da matriz de impedância. Como dito, três indicadores foram criados para serem utilizados como proxy para impedância no fluxo de comércio entre as microrregiões. Um deles é o custo mínimo inter-regional de transporte em $\mathrm{R} \$$ /tonelada para cada produto. Assim, o custo de transferência inter-regional foi representado por essa medida. A restrição utilizada para a geração do fluxo de comércio foi a distância entre as microrregiões. Nesse caso, tal indicador cumpriu bem o objetivo porque o cálculo do fluxo de comércio exigia o uso de uma medida invariante entre os pares de origem-destino, o que é o caso da distância. No entanto, o custo de transferência varia de produto para produto em razão das suas características intrínsecas. Por isso, o custo mínimo foi escolhido em detrimento da distância e do tempo mínimo de viagem.

No conjunto de informações geradas no estudo do PNLT de 2007, 25 tipos diferentes de fluxos de custo mínimo estavam disponíveis. Neste estudo, cada tipo de fluxo de custo mínimo foi associado a alguns produtos, considerando a proximidade em termos econômicos e as características de condições de transporte do fluxo e do produto. Para a 
criação da variável Custo, o critério de associação referido anteriormente foi mantido, de modo que cada produto foi associado a um desses tipos diferentes de custo. A consolidação do fluxo de custo mínimo exigiu duas etapas de trabalho computacional: (i) a primeira foi a estruturação do fluxo de custo entre os pares de origem-destino para o formato matricial, de forma a compreender a totalidade das microrregiões, e não apenas aquelas cujo fluxo era não nulo; (ii) em seguida, o empilhamento das colunas em apenas um vetor, assim como foi realizado para a consolidação da variável $Q$.

\section{3_Demais variáveis: PIB e densidade}

A variável PIB foi obtidas diretamente por meio do endereço eletrônico do IpeaData, e a variável Densidade foi construída com base nos dados também desse endereço acerca da população e da área. Essas variáveis, ao contrário das outras duas ( $Q$ e Custo), não representam características específicas dos produtos, mas sim das regiões de análise. Dessa maneira, tais variáveis são constantes no processo de estimação de todos os produtos.

Finalmente, vale destacar que parte do esforço desta pesquisa refere-se à obtenção e à geração dos dados relativos às variáveis utilizadas para estimar as elasticidades regionais de Armington. Esse banco de dados possui a consistência necessária para que se adote um procedimento de estimação model-consistent de tal forma que as estimativas das elasticidades de comércio regional sejam subsequentemente utilizadas em um modelo espacial EGC calibrado com as mesmas informações.

\section{3_Metodologia}

Esta seção descreve a equação usada para estimar as elasticidades de comércio regional ou elasticidades regionais de Armington. Adicionalmente, são apresentadas as duas equações principais que forneceram a base de cálculo para a geração do resultado inicial dos fluxos de comércio inter-regional e preenchimento das Shin tables (ver seção anterior). O procedimento das etapas executadas, bem como a trajetória de trabalho para a geração do resultado final, alcançando as matrizes de fluxos de comércio entre as microrregiões para os produtos, foi descrito na seção anterior deste trabalho.

Para a obtenção da equação final, o procedimento utilizado foi realizado com base na conjunção da metodologia desenvolvida por Armington (1969) e Bilgic et al. (2002). Isso possibilitou construir um método deduzido relativamente de forma simples para aplicação quando se deseja estimar elasticidades de substituição tendo como referência a produção de diferentes bens e regiões dentro de uma economia nacional. A diferença essencial deste trabalho para o estudo de Bilgic et al. (2002) é a forma com que as variáveis foram classificadas e implementadas, sendo uma versão alternativa para a construção dessas. Portanto, a abordagem aplicada neste estudo apresenta-se não muito distinta do estudo de Bilgic et al. (2002), como será mostrado a seguir.

Assim, com base em Armington (1969), define-se inicialmente:

$$
X_{i}=\left(X_{i 1}, X_{i 2}, \ldots, X_{i m}\right), i=1,2, \ldots, n
$$

Onde $X_{i j}$ é assumido ser um substituto imperfeito para $X_{i k}$ $(j \neq k)$ do ponto de vista dos compradores em qualquer região; $X_{i}$ refere-se aos produtos ou grupo de produtos ofertados por diferentes regiões $j=1,2, \ldots, m$.

Define-se uma função de satisfação de comportamento genérico dos compradores, dada a seleção disponível de produtos e preços no mercado. Essa função tem por objetivo captar a forma como os compradores desejam 
compor sua cesta de produtos, tendo em vista a obtenção de níveis mais elevados de satisfação tanto quanto seja possível, considerando suas restrições. Supõe-se que tal satisfação seja dada por um índice $U$; assim, as funções de demanda podem ser derivadas como consequência da resolução do problema de maximização de $U$ sujeita a restrição com que esses se deparam.

De forma genérica, o formato da função de satisfação (utilidade) $U$ pode ser definido como:

$$
U=U(X)
$$

E a restrição orçamentária como:

$$
D=P X^{\prime}
$$

Onde $P$ representa o vetor de preços

$$
\left(P_{11}, P_{12}, \ldots, P_{1 m}, P_{21}, P_{22}, \ldots, P_{2 m}, \ldots, P_{n 1}, P_{n 2}, \ldots, P_{n m}\right) \text {. }
$$

Armington (1969) mostrou que, sobre a hipótese de independência, se tem que o termo $U=U\left(X_{11}, X_{12}, \ldots, X_{1 m}\right.$, $\left., X_{21}, X_{22}, \ldots, X_{2 m}, \ldots, X_{n 1}, X_{n 2}, \ldots, X_{n m}\right)$ colapsa para:

$$
\begin{aligned}
& X_{i}=\phi_{i}\left(X_{i 1}, X_{i 2}, \ldots, X_{i m}\right), \\
& \text { para } i=1,2, \ldots, n \text { produtos }
\end{aligned}
$$

A hipótese de independência, em outras palavras, significa que a taxa marginal de substituição entre quaisquer dois produtos do mesmo tipo seja independente das quantidades dos produtos de outros tipos. Se isso ocorre, então, a equação (4) pode se sustentada. Associado a (4), existe um vetor de preços, $P_{i}=\left(P_{i 1}, P_{i 2}, \ldots, P_{i m}\right)$, que é consistente com o equilíbrio ótimo de mercado de produtos levando em conta todas as regiões. ${ }^{2}$
Neste contexto, a restrição orçamentária tem a seguinte forma:

$$
M=\sum_{i=1}^{n} \sum_{k=1}^{m} P_{i k} X_{i k}=\sum_{i=1}^{n} P_{i} X_{i}
$$

A demanda por qualquer produto, $X_{i j}$, pode ser obtida minimizando $\mathrm{M}$ sujeito à restrição . Foram assumidos que $X_{i}=\phi_{i}\left(X_{i 1}, X_{i 2}, \ldots, X_{i m}\right)$ os $\varphi$ i's possuem comportamentos descritos por funções de elasticidade constante de substituição (CES). Assim, a equação (4) pode ser reescrita como:

$$
X_{i}=\left[b_{i 1} X_{i 1}^{-\rho_{i}}+b_{i 2} X_{i 2}^{-\rho_{i}}+\cdots+b_{i m} X_{i m}^{-\rho_{i}}\right]^{-\frac{1}{\rho_{i}}}
$$

Onde $\sum_{k=1}^{m} b_{i k}=1$ e $\rho_{i}$ é uma constante maior que -1 .

Com base na derivação das demandas de uma função CES, apresentada em Dixon et al. (1992), o resultado das condições de primeira ordem fornece que:

$$
\frac{X_{i j}}{X_{i k}}=\left(\frac{b_{i k}}{b_{i j}}\right)^{\sigma_{i}}\left(\frac{P_{i j}}{P_{i k}}\right)^{\sigma_{i}}, k=1,2, \ldots, m
$$

Onde $\frac{1}{1+\rho_{i}}=\sigma_{i}$ é a elasticidade de substituição no mercado do produto $i$.

A equação (7) pode ser reescrita da seguinte forma:

$$
\frac{X_{i j}}{X_{i k}}=a^{\sigma_{i}}\left(\frac{P_{i j}}{P_{i k}}\right)^{\sigma_{i}} \text {, onde } a=\left(\frac{b_{i k}}{b_{i j}}\right)
$$


De posse da equação (8), isto é, das demandas ótimas por produtos por parte dos compradores, adota-se neste ponto da trajetória de definição do modelo a sugestão de Bilgic et al. (2002), fazendo com que:

$$
a=\exp \left(\alpha_{o}+\alpha_{1} \ln W_{1 j}+\alpha_{2} \ln W_{2 j}\right)
$$

Substituindo (9) em (8) e aplicando logaritmo natural no resultado obtido desta substituição, tem-se que:

$$
\begin{aligned}
& \ln \left(\frac{X_{i j}}{X_{i k}}\right)=\sigma_{i}\left(\alpha_{0}+\alpha_{1} \ln W_{1 j}+\alpha_{2} \ln W_{2 j}\right)+\sigma_{i} \ln \left(\frac{P_{i j}}{P_{i k}}\right) \\
& \ln \left(\frac{X_{i j}}{X_{i k}}\right)=\beta_{0 i}+\beta_{1 i} \ln W_{1 j}+\beta_{2 i} \ln W_{2 j}+\beta_{3 i} \ln \left(\frac{P_{i j}}{P_{i k}}\right)
\end{aligned}
$$

Onde $\beta_{\mathrm{o} i}=\sigma_{i} \alpha_{0}, \beta_{1 i}=\sigma_{i} \alpha_{1}, \beta_{2 i}=\sigma_{i} \alpha_{2}$ e $\beta_{3 i}=\sigma_{i}$. Vale destacar que $i=1,2, \ldots, n$ representa os $\mathrm{n}$ produtos. Assim, para cada produto, há uma elasticidade de substituição correspondente, constante entre qualquer par de regiões de origem-destino. $O$ termo de interesse é $\sigma_{i}=\beta_{3 i}$, que fornece a medida de sensibilidade do comércio inter-regional ao custo de transação, em termos relativos. Uma hipótese relevante sobre essa medida é que bens produzidos em diferentes regiões são substitutos imperfeitos (hipótese de Armington).

A adoção da sugestão de Bilgic et al. (2002) segue a interpretação da equação (10). Neste sentido, tem-se que:

i) o termo $X_{i j} / X_{i k}$ representa a razão do produto entre os pares de regiões de origem-destino. Tal medida será a proxy para o nível do fluxo de comércio entre as microrregiões no território brasileiro. ii) o termo $P_{i j} / P_{i k}$ representa o preço relativo do produto, tendo como referência os pares de regiões de origem-destino. Tal medida será a proxy para o custo de transação inter-regional.

iii) o termo $W_{1 j}$ representa o PIB da região de origem do fluxo de comércio. Essa será a proxy para o tamanho de mercado. Tal variável tem como função indicar a capacidade de produção da região e, com isso, a capacidade de a região atender, em parte, a própria demanda.

iv) o termo $W_{2 j}$ representa a densidade da região de destino das vendas, funcionando como medida relativa entre o fluxo de comércio e o tamanho do mercado consumidor. Tal variável tem como função servir como indicativo do fator de isolamento da região. Espera-se que regiões com população mais esparsamente distribuída produzam bens principalmente voltados para consumo próprio (Bilgic et al., 2002).

Por fim, a equação (10), após substituição da descrição de seus termos e adição do termo de erro $\left(\varepsilon_{i}\right)$, pode ser retratada como abaixo:

$$
\begin{array}{r}
\ln (Q)=c_{i}+\beta_{3 i} \ln (\text { Custo })+\beta_{1 i} \ln (\text { PIB })+ \\
+\beta_{2 i} \ln (\text { Densidade })+\varepsilon_{i}
\end{array}
$$

Onde $Q$ segue o termo especificado em (i), Custo o termo em (ii), PIB o termo em (iii), Densidade o termo em (iv) e $c_{i}=\beta_{\mathrm{o} i}$.

A metodologia descreve de forma simples o procedimento realizado para a obtenção da equação a ser estimada. $\mathrm{O}$ valor existente quanto à descrição dessa metodologia reside no fato de ela associar o trabalho desenvolvido por Armington (1969) à flexibilidade apontada por Bilgic et al. (2002) quanto à forma com que as variáveis deduzidas no processo de oti- 
mização dos compradores podem ser definidas. Essa síntese metodológica tornou possível a obtenção da equação final (11) a ser estimada, adotando-se definições próprias para o caso de uma análise inter-regional aplicada a um contexto nacional, que se mostrou um pouco diferente ao trabalho de Bilgic et al. (2002).

Assim, as diferenças desse mencionado estudo para o presente trabalho podem ser elencadas de forma resumida: i) a abordagem desenvolvida para o presente trabalho exigiu aplicação alternativa quanto às variáveis a serem empregadas no modelo, especialmente com relação aos termos $Q$ e Custo - foram utilizadas proporções em relação ao total do fluxo relativo às regiões compradoras. A forma adotada de implementação das variáveis criou um sistema de dados empilhados; e ii) o presente estudo deixa explícita na equação a ser estimada a dimensão produto, ao especificar de forma clara o subscrito $i$, indicando que, para cada produto, uma elasticidade de interesse será estimada $\left(\beta_{3 i}\right)$.

A necessidade da documentação dessa metodologia mostra-se importante, uma vez que, além das diferenças mencionadas para o trabalho de Bilgic et al. (2002), os estudos realizados e aplicados ao caso da economia brasilei- ra não apresentaram de forma explícita tal procedimento, apesar de a implementação ser parecida com aquela sugerida pela equação (11).

A equação (11) foi estimada pelo método de Mínimos Quadrados Ordinários (MQO), e a estrutura do banco de dados na forma empilhada forneceu uma propriedade interessante: como as informações são referentes a um ano, tem-se uma disposição de cross-section, mas na forma de um sistema que foi estimado considerando o conjunto completo de informações. Isso ocorreu porque os dados são dispostos em pares de origem e destino; assim, para cada unidade de cross-section, que são as microrregiões, obtêm-se as informações da microrregião contra as informações de todas as outras. Ao considerar o conjunto completo de informações na estimação, ao invés de considerar regressões individuais para cada microrregião, é possível obter ganho de eficiência para as estimativas. ${ }^{3} \mathrm{~A}$ seguir, são apresentadas as equações utilizadas para a geração inicial das estimativas do fluxo de comércio inter-regional. Mais detalhes sobre o procedimento podem ser encontrados em Dixon e Rimmer (2004).

$$
\operatorname{SHIN}(c, s, g, g)=\min \left\{\frac{O(c, s, g)}{D(c, s, g)}, 1\right\} \times F(c, s)
$$


Onde SHIN é a variável que representa a proxy para o fluxo de comércio; $O$ é a matriz de oferta; $D$ é a matriz de demanda; $F$ é o vetor de coeficientes, que sinaliza quão comercializável é cada produto; e Dist é a matriz de distância. Os valores entre parênteses indicam o dimensionamento do fluxo indicado pelas matrizes, considerando os produtos e as microrregiões. $\mathrm{O} c$ refere-se aos produtos, enquanto $s, r, g$, $q$ e $v$ representam a regiões, sendo que $s$ e $v$ fazem parte do conjunto de regiões de origem, e $r$ e $g$, assim como $q$, fazem parte do conjunto de regiões de destino $(R E G)$. A forma de identificação das regiões foi necessária para que houvesse distinção quanto à referência relevante. Por exemplo, a variável $\operatorname{SHIN}(c, s, g, g)$ indica que apenas termos da diagonal principal estão sendo calculados com base na equação (12), ao passo que a variável $\operatorname{SHIN}(c, s, r, g)$ indica que os termos fora da diagonal principal estão sendo calculados, com base na equação (13), por isso deve-se considerar a distância entre as regiões.

Algumas conclusões simples podem ser tiradas analisando-se as equações acima.Seo valor inicial de $\operatorname{SHIN}(c, s, g, g)$ for alto quer dizer que a região $g$ é um importante fornecedor do produto $c$, e, neste caso, o numerador da equação (12) é maior que o denominador, e $c$ parece ser um produto pouco comercializável. Na equação (13), um alto valor de $\operatorname{SHIN}(c, s, r, g)$, com $r \neq g$, indica que $r$ e $g$ são microrregiões próximas uma da outra, e $r$ é uma importante região fornecedora de $c$; neste caso, $\operatorname{Dist}(r, g)$ e $\operatorname{SHIN}(c, s, g, g)$ são pequenos, e $O(c, s, r)$ é grande, e $c$ parece ser um produto com alto grau de comércio.

\section{4_Resultados}

Os resultados das estimações realizadas com base na equação (11) são apresentados na Tabela 1. Para facilitar a análise, tais resultados foram destacados segundo quatro grupos de grandes setores: produtos associados ao setor agrícola (1 ao 18), ao setor extrativo (19 ao 23), ao setor industrial (24 ao 91) e ao setor de serviços (92 ao 110). As estimativas de interesse, isto é, as elasticidades de comércio inter-regional, estão computadas na coluna de coeficientes referente à variável $\ln$ (Custos). Em geral, as estimativas têm o sinal negativo esperado, indicando que os maiores custos de transação dos produtos estão associados a menores fluxos de comércio, uma vez que aquela variável desempenha o papel de restrição ao comércio, ao mesmo tempo em que sinaliza as dificuldades intrínsecas em cada fluxo entre os pares de origem e destino.

Antes de analisar os resultados específicos de cada grupo de produtos, cabe ressaltar os resultados das outras variáveis, que funcionaram como controles na geração das elasticidades de comércio inter-regional, bem como da significância dos coeficientes e sua possível relação com a amostra e o grau de ajustamento $\left(R^{2}\right)$. Os coeficientes relacionados à variável $\ln (P I B)$ apresentaram em sua totalidade estimativas positivas, o que era esperado, uma vez que maiores valores de PIB estão associados a maior capacidade de produção da região e, consequentemente, maior capacidade de realização de comércio.

Os coeficientes associados à variável $\ln$ (Densidade) apresentaram valores negativos em sua maioria. Este resultado sugere que, quanto mais densa a região (o que captaria maior potencial de complexidade produtiva), menor sua dependência com relação aos bens produzidos fora da região. Esse mesmo resultado também foi obtido por Bilgic et al. (2002).

Uma análise conjunta da significância dos coeficientes das variáveis utilizadas pode ser interessante para verificar o efeito predominante. Quase todos os coeficientes estimados foram significativos ao nível de 1\%, com exceção daqueles sinalizados, caso fossem não significativos a 10\% (sinalizados $\left.\operatorname{com}^{\star}\right)$, significativos a $10 \%\left(\right.$ sinalizados com $\left.{ }^{\star *}\right)$ e significati- 
vos a $5 \%$ (sinalizados com ${ }^{\star * *}$ ). A variável $\ln$ (Densidade) foi a que teve maior número de coeficientes não significativos a $10 \%$, sete no total. A variável $\ln (P I B)$ teve apenas um coeficiente não significativo a $1 \%$, mas significativo a $5 \%$, relativo ao produto Carvão mineral. Com relação à variável $\ln$ (Custo) apenas o coeficiente do produto Trigo em grão e outros cereais, único que apresentou sinal contrário ao esperado, foi não significativo a 10\%, enquanto os coeficientes associados aos produtos Carvão mineral e Minerais metálicos não ferrosos foram significativos a $5 \%$ e $10 \%$, respectivamente. Todos os demais coeficientes dos produtos relacionados a essa variável foram significativos a $1 \%$. Isso demonstra que as estimativas das elasticidades de comércio inter-regional são, em quase sua totalidade, significativas a $1 \%$.

Vale destacar uma característica inerente ao processo de estimação dos modelos. Os produtos possuem especificidades, a mais importante para o presente estudo acerca do seu grau de comercialização. Isso também é refletido no banco de dados do modelo estimado para cada produto. Dessa forma, pode-se observar que os produtos Minério de ferro, Carvão mineral e Minerais metálicos não ferrosos possuem menos informações na amostra, uma vez que tanto sua produção como seus mercados são concentrados espacialmente e, por isso, apresentam poucos pares de origem-destino na amostra. Essas atividades estão relacionadas com a atividade de extração, localizadas em regiões específicas dotadas do recurso natural. Dessa forma, tanto a matriz do fluxo de comércio quanto a matriz de custo de transporte entre pares de origem-destino funcionam como restrição na amostra, uma vez que apenas o cruzamento de informações não nulas é considerado no processo de estimação dos coeficientes. O grau de ajustamento dos modelos retratado pelo $R^{2}$ também sinaliza esse fato.

As estimativas das elasticidades de comércio inter-regional para os produtos agrícolas apresentaram valores mais expressivos para os produtos Frutas cítricas $(-2,505)$, Pesca e aquicultura $(-2,376)$ e Ovos de galinha e de outras aves $(-2,304)$, respectivamente. $O$ coeficiente médio dos produtos agrícolas foi de -1,894, portanto, mais elástico do que aqueles apresentados Bilgic et al. (2002) (-1,477). A Tabela 2 sistematiza os resultados dos coeficientes médios dos setores encontrados pelo presente estudo e por outros estudos que objetivaram estimar as elasticidades do comércio regional. As estimativas das elasticidades deste estudo foram calculadas para medir a sensibilidade do comércio inter-regional entre bens, mas realizadas levando em conta diferentes contextos de preparação dos dados (e.g. nível de desagregação setorial e aplicação a um cenário econômico distinto do brasileiro). Isso pode fazer com as que estimativas não sejam completamente comparáveis, em razão de aquele trabalho focar no comércio inter-regional de um país desenvolvido, que possui características distintas do Brasil com relação à infraestrutura de transporte, escala de mercado e nível de renda.

O valor do coeficiente médio do setor agrícola obtido no presente estudo, por sua vez, foi mais elástico do que aquele encontrado por Haddad (2004) (-1,720) e menos elástico do que o encontrado por Faria (2009) (-3,887), trabalhos esses que calcularam estimativas para as elasticidades de comércio inter-regional com base em uma abordagem similar a utilizada neste estudo, apesar de utilizarem agregações regionais distintas. No caso de Haddad (2004), as elasticidades foram estimadas em um contexto de comércio interestadual, para o ano de 1996. Ressalta-se, para fins de contextualização, que, ceteris paribus, a dependência espacial tende a ser maior em níveis hierárquicos inferiores (desagregação espacial mais fina), o que levaria à expectativa de obtenção de magnitudes das elasticidades tanto maiores (em módulo) quanto menores forem as áreas de análise.

As elasticidades dos produtos que compõem a indústria foram mais expressivas para os produtos Fabricação de 
resina e elastômeros (-2,097), Bebidas $(-2,096)$ e Produtos químicos orgânicos $(-2,050)$, respectivamente. $O$ coeficiente médio da indústria foi igual a -1,820, valor mais elástico do que aqueles encontrados por Bilgic et al. (2002) (-0,840), Faria (2009) (-0,862), Turner et al. (2012) (-1,057) e Tooze (1976), supondo o caso de retornos constantes de escala $(-1,125)$ e supondo retornos não constantes de escala $(-0,901)$. No caso do estudo de Tooze (1976), há complicações adicionais para fazer comparações em relação àquelas mencionadas anteriormente: observa-se diferença quanto ao procedimento metodológico utilizado e ao contexto histórico de análise, bastante distinto do atual. No entanto, o coeficiente médio da indústria foi menos elástico do que o calculado por Haddad (2004) (-2,079).

Para os produtos do setor extrativo, tem-se coeficiente médio igual a -1,177, menos elástico do que o coeficiente médio do mesmo setor encontrado por Bilgic et al. (2002)
$(-2,151)$ e Faria (2009) (-1,557), e mais elástico do que o coeficiente encontrado por Turner et al. (2012) (-0,963). Apenas a fim de reflexão, o coeficiente médio dos setores extrativos observado no trabalho de Reinert e Roland-Holst (1992) foi igual a -0,758. No entanto, a comparação desse resultado com o obtido no presente estudo não deve ser feita, uma vez que os trabalhos estimam elasticidades com base em diferentes fluxos de comércio. Comparações desse tipo mereceriam maior atenção para análises, por exemplo, entre o grau de dependência das regiões com relação aos produtos no comércio regional e no comércio com o restante do mundo. Ademais, de acordo com Partridge e Rickman (1998), em razão de regiões dentro de um contexto nacional serem mais próximas umas das outras, na maioria dos casos, e das barreiras artificiais impostas ao comércio internacional, as elasticidades do comércio regional tendem a ser maiores que as elasticidades do comércio de bens entre diferentes países.

Tabela 1_Estimativas de elasticidades de comércio regional para o Brasil: Variável Dependente - $\ln (Q)$

\begin{tabular}{|c|c|c|c|c|c|c|c|c|c|c|c|}
\hline & & Constante & & $\ln$ (Custos) & & $\ln (\mathrm{PIB})$ & & In(Densida & ade) & & (Contunua) \\
\hline & & Coeficiente & Erro-padrão & Coeficiente & Erro-padrão & Coeficiente & Erro-padrão & Coeficiente & Erro-padrão & & Amostra \\
\hline 1 & Arroz em casca & $-2,845$ & 0,039 & $-1,318$ & 0,007 & 1,166 & 0,002 & 0,031 & 0,003 & 0,826 & 63656 \\
\hline 2 & Milho em grão & $-3,348$ & 0,105 & $-1,239$ & 0,020 & 0,832 & 0,009 & $-0,053$ & 0,008 & 0,496 & 11960 \\
\hline 3 & Trigo em grão e outros cereais & $-8,483$ & 0,047 & $0,002^{*}$ & 0,008 & 1,149 & 0,003 & $-0,017$ & 0,004 & 0,823 & 29604 \\
\hline 4 & Cana-de-açúcar & 1,679 & 0,042 & $-2,266$ & 0,008 & 1,043 & 0,001 & $-0,352$ & 0,003 & 0,830 & 152145 \\
\hline 5 & Soja em grão & $-3,476$ & 0,254 & $-1,800$ & 0,050 & 1,138 & 0,015 & $-0,024 \%$ & 0,025 & 0,785 & 1896 \\
\hline 6 & $\begin{array}{l}\text { Outros produtos e } \\
\text { serviços da lavoura }\end{array}$ & $-2,329$ & 0,034 & $-1,656$ & 0,006 & 0,870 & 0,003 & $-0,084$ & 0,002 & 0,543 & 171687 \\
\hline 7 & Mandioca & $-0,705$ & 0,038 & $-1,807$ & 0,007 & 1,181 & 0,002 & 0,053 & 0,002 & 0,689 & 170262 \\
\hline 8 & Fumo em folha & $-7,929$ & 0,066 & $-0,137$ & 0,012 & 1,009 & 0,003 & $-0,047$ & 0,005 & 0,808 & 28961 \\
\hline 9 & Algodão herbáceo & $-2,369$ & 0,069 & $-1,374$ & 0,013 & 1,141 & 0,003 & 0,050 & 0,005 & 0,895 & 19398 \\
\hline
\end{tabular}




\begin{tabular}{|c|c|c|c|c|c|c|c|c|c|c|c|}
\hline \multirow{2}{*}{\multicolumn{2}{|c|}{ Produtos }} & \multicolumn{2}{|l|}{ Constante } & \multicolumn{2}{|l|}{ In(Custos) } & \multicolumn{2}{|l|}{$\ln (P \mid B)$} & \multicolumn{2}{|c|}{ In(Densidade) } & \multirow{2}{*}{$\mathrm{R} 2$} & \multirow{2}{*}{ (Contunua) } \\
\hline & & Coeficiente & Erro-padrão & Coeficiente & Erro-padrão & Coeficiente & Erro-padrão & Coeficiente & Erro-padrão & & \\
\hline 10 & Frutas cítricas & 3,720 & 0,045 & $-2,505$ & 0,008 & 1,114 & 0,002 & $-0,395$ & 0,003 & 0,795 & 155624 \\
\hline 11 & Café em grão & $-5,848$ & 0,106 & $-0,877$ & 0,019 & 1,291 & 0,004 & $-0,198$ & 0,007 & 0,805 & 25959 \\
\hline 12 & $\begin{array}{l}\text { Produtos da exploração florestal } \\
\text { e da silvicultura }\end{array}$ & $-2,685$ & 0,035 & $-1,407$ & 0,006 & 0,978 & 0,003 & $-0,089$ & 0,003 & 0,634 & 111901 \\
\hline 13 & Bovinos e outros animais vivos & $-3,321$ & 0,033 & $-1,832$ & 0,006 & 1,198 & 0,003 & 0,194 & 0,002 & 0,693 & 129981 \\
\hline 14 & Leite de vaca e de outros animais & $-0,241$ & 0,036 & $-2,084$ & 0,006 & 1,027 & 0,002 & $-0,025$ & 0,002 & 0,751 & 129446 \\
\hline 15 & Suínos vivos & 0,223 & 0,037 & $-1,962$ & 0,007 & 1,056 & 0,003 & 0,022 & 0,003 & 0,604 & 129969 \\
\hline 16 & Aves vivas & 1,341 & 0,042 & $-2,241$ & 0,007 & 0,935 & 0,003 & $-0,185$ & 0,003 & 0,661 & 129896 \\
\hline 17 & Ovos de galinha e de outras aves & 2,833 & 0,032 & $-2,304$ & 0,006 & 0,983 & 0,002 & $-0,339$ & 0,002 & 0,799 & 129896 \\
\hline 18 & Pesca e aquicultura & 3,220 & 0,053 & $-2,376$ & 0,010 & 1,259 & 0,003 & $-0,217$ & 0,004 & 0,719 & 68067 \\
\hline 19 & Petróleo e gás natural & $-3,020$ & 0,297 & $-1,508$ & 0,054 & 1,158 & 0,016 & $-0,469$ & 0,021 & 0,694 & 2566 \\
\hline 20 & Minério de ferro & $-5,899$ & 0,666 & $-1,124$ & 0,118 & 0,929 & 0,042 & $0,050 \%$ & 0,060 & 0,812 & 177 \\
\hline 21 & Carvão mineral & $-3,335$ & 0,920 & $-0,137^{\text {***\% }}$ & 0,060 & 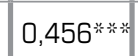 & 0,198 & $0,015^{*}$ & 0,029 & 0,059 & 154 \\
\hline 22 & Minerais metálicos não ferrosos & $-6,322$ & 0,800 & $-1,275^{* *}$ & 0,329 & 1,350 & 0,093 & $0,044 *$ & 0,176 & 0,993 & 6 \\
\hline 23 & Minerais não metálicos & $-0,339 *$ & 0,384 & $-1,842$ & 0,074 & 1,271 & 0,027 & $-0,447$ & 0,028 & 0,706 & 1188 \\
\hline 24 & $\begin{array}{l}\text { Abate e preparação de } \\
\text { produtos de carne }\end{array}$ & $-4,257$ & 0,070 & $-1,702$ & 0,013 & 1,252 & 0,004 & $-0,008 \%$ & 0,005 & 0,770 & 33067 \\
\hline 25 & $\begin{array}{l}\text { Carne de suíno fresca, } \\
\text { refrigerada ou congelada }\end{array}$ & $-3,924$ & 0,082 & $-1,074$ & 0,015 & 1,140 & 0,004 & $-0,282$ & 0,006 & 0,722 & 33067 \\
\hline 26 & $\begin{array}{l}\text { Carne de aves fresca, } \\
\text { refrigerada ou congelada }\end{array}$ & $-1,668$ & 0,074 & $-1,524$ & 0,013 & 0,955 & 0,004 & $-0,392$ & 0,005 & 0,703 & 32726 \\
\hline 27 & Pescado industrializado & 3,042 & 0,133 & $-2,275$ & 0,025 & 1,051 & 0,009 & $-0,192$ & 0,010 & 0,652 & 11459 \\
\hline 28 & $\begin{array}{l}\text { Conservas de frutas, legumes e } \\
\text { outros vegetais }\end{array}$ & $-0,028 *$ & 0,136 & $-2,090$ & 0,026 & 0,848 & 0,008 & $-0,150$ & 0,010 & 0,438 & 21905 \\
\hline 29 & $\begin{array}{l}\text { Óleo de soja em bruto e tortas, } \\
\text { bagaços e farelo de soja }\end{array}$ & $-6,877$ & 0,137 & $-0,742$ & 0,019 & 1,015 & 0,017 & $-0,020 *$ & 0,008 & 0,316 & 10026 \\
\hline 30 & $\begin{array}{l}\text { Outros óleos e gordura vegetal e } \\
\text { animal exclusive milho }\end{array}$ & 0,925 & 0,113 & $-2,165$ & 0,022 & 1,016 & 0,006 & $-0,032$ & 0,008 & 0,733 & 13241 \\
\hline 31 & Óleo de soja refinado & $-1,946$ & 0,077 & $-1,502$ & 0,014 & 1,030 & 0,004 & $-0,119$ & 0,005 & 0,661 & 39633 \\
\hline 32 & $\begin{array}{l}\text { Leite resfriado, esterilizado e } \\
\text { pasteurizado }\end{array}$ & $0,048 *$ & 0,070 & $-2,102$ & 0,013 & 0,924 & 0,005 & $-0,094$ & 0,005 & 0,675 & 27996 \\
\hline
\end{tabular}




\begin{tabular}{|c|c|c|c|c|c|c|c|c|c|c|c|}
\hline \multirow{2}{*}{\multicolumn{2}{|c|}{ Produtos }} & \multicolumn{2}{|l|}{ Constante } & \multicolumn{2}{|l|}{ In(Custos) } & \multicolumn{2}{|l|}{$\ln (\mathrm{PIB})$} & \multicolumn{2}{|c|}{ In(Densidade) } & & \multirow{2}{*}{ Amostra } \\
\hline & & Coeficiente & Erro-padrão & Coeficiente & Erro-padrão & Coeficiente & Erro-padrão & Coeficiente & Erro-padrão & & \\
\hline 33 & Produtos do laticínio e sorvetes & $-0,452$ & 0,072 & $-2,082$ & 0,013 & 0,914 & 0,005 & $-0,074$ & 0,005 & 0,664 & 27996 \\
\hline 34 & $\begin{array}{l}\text { Arroz beneficiado e } \\
\text { produtos derivados }\end{array}$ & $-2,386$ & 0,097 & $-1,527$ & 0,018 & 1,178 & 0,004 & $-0,155$ & 0,007 & 0,749 & 26153 \\
\hline 35 & Farinha de trigo e derivados & 3,460 & 0,061 & $-2,392$ & 0,011 & 1,016 & 0,004 & $-0,530$ & 0,004 & 0,747 & 44640 \\
\hline 36 & Farinha de mandioca e outros & $-0,204$ & 0,070 & $-1,750$ & 0,012 & 1,040 & 0,003 & $-0,340$ & 0,005 & 0,706 & 46003 \\
\hline 37 & $\begin{array}{l}\text { Óleos de milho, amidos e } \\
\text { féculas vegetais e rações }\end{array}$ & 2,124 & 0,073 & $-2,422$ & 0,013 & 1,111 & 0,003 & $-0,499$ & 0,005 & 0,800 & 38712 \\
\hline 38 & $\begin{array}{l}\text { Produtos das usinas e } \\
\text { do refino de açúcar }\end{array}$ & $-2,632$ & 0,122 & $-1,242$ & 0,020 & 0,886 & 0,011 & $-0,314$ & 0,008 & 0,520 & 9280 \\
\hline 39 & Café torrado e moído & 3,836 & 0,073 & $-2,534$ & 0,013 & 1,078 & 0,004 & $-0,487$ & 0,005 & 0,739 & 46954 \\
\hline 40 & Café solúvel & $-3,152$ & 0,091 & $-0,859$ & 0,016 & 1,041 & 0,004 & $-0,261$ & 0,006 & 0,709 & 30488 \\
\hline 41 & Outros produtos alimentares & 1,016 & 0,064 & $-2,196$ & 0,012 & 0,892 & 0,004 & $-0,395$ & 0,004 & 0,781 & 28879 \\
\hline 42 & Bebidas & 1,900 & 0,085 & $-2,516$ & 0,016 & 0,916 & 0,005 & $-0,299$ & 0,006 & 0,712 & 24343 \\
\hline 43 & Produtos do fumo & 1,314 & 0,065 & $-2,013$ & 0,011 & 0,933 & 0,003 & $-0,397$ & 0,004 & 0,697 & 46628 \\
\hline 44 & $\begin{array}{l}\text { Beneficiamento de algodão e de } \\
\text { outros têxteis e fiação }\end{array}$ & 3,638 & 0,117 & $-2,540$ & 0,022 & 0,979 & 0,006 & $-0,408$ & 0,008 & 0,724 & 16924 \\
\hline 45 & Tecelagem & 3,481 & 0,129 & $-2,434$ & 0,024 & 1,031 & 0,007 & $-0,555$ & 0,009 & 0,759 & 11671 \\
\hline 46 & $\begin{array}{l}\text { Fabricação outros produtos } \\
\text { têxteis }\end{array}$ & $-0,023 *$ & 0,109 & $-1,908$ & 0,020 & 0,977 & 0,006 & $-0,425$ & 0,008 & 0,764 & 12937 \\
\hline 47 & Artigos do vestuário e acessórios & 0,309 & 0,073 & $-2,104$ & 0,014 & 0,931 & 0,004 & $-0,378$ & 0,005 & 0,772 & 28391 \\
\hline 48 & $\begin{array}{l}\text { Preparação do couro e fabricação } \\
\text { de artefatos - exclusive calçados }\end{array}$ & $-0,335$ & 0,093 & $-1,949$ & 0,018 & 0,938 & 0,006 & $-0,085$ & 0,007 & 0,633 & 22627 \\
\hline 49 & Fabricação de calçados & 0,833 & 0,098 & $-2,281$ & 0,019 & 1,009 & 0,005 & $-0,200$ & 0,007 & 0,733 & 22295 \\
\hline 50 & $\begin{array}{l}\text { Produtos de madeira } \\
\text { - exclusive móveis }\end{array}$ & $-0,186 \%$ & 0,073 & $-2,151$ & 0,014 & 0,867 & 0,005 & $0,009 *$ & 0,005 & 0,653 & 27958 \\
\hline 51 & $\begin{array}{l}\text { Celulose e outras pastas para } \\
\text { fabricação de papel }\end{array}$ & $-7,654$ & 0,738 & $-0,889$ & 0,121 & 1,087 & 0,053 & 0,183 & 0,053 & 0,486 & 581 \\
\hline 52 & $\begin{array}{l}\text { Papel e papelão, } \\
\text { embalagens e artefatos }\end{array}$ & $-1,141$ & 0,106 & $-1,875$ & 0,020 & 1,011 & 0,006 & $-0,322$ & 0,008 & 0,690 & 19018 \\
\hline 53 & $\begin{array}{l}\text { Jornais, revistas, discos e outros } \\
\text { produtos gravados }\end{array}$ & 0,196 & 0,072 & $-2,047$ & 0,013 & 0,882 & 0,004 & $-0,338$ & 0,005 & 0,708 & 27908 \\
\hline 54 & Gás liquefeito de petróleo & $-0,526$ & 0,248 & $-1,541$ & 0,031 & 0,913 & 0,030 & $-0,328$ & 0,013 & 0,402 & 5115 \\
\hline
\end{tabular}




\begin{tabular}{|c|c|c|c|c|c|c|c|c|c|c|c|}
\hline \multirow{2}{*}{\multicolumn{2}{|c|}{ Produtos }} & \multicolumn{2}{|l|}{ Constante } & \multicolumn{2}{|l|}{ In(Custos) } & \multicolumn{2}{|l|}{$\ln (P \mid B)$} & \multicolumn{2}{|c|}{ In(Densidade) } & \multirow{2}{*}{$\mathrm{R} 2$} & \multirow{2}{*}{ Amostra } \\
\hline & & Coeficiente & Erro-padrão & Coeficiente & Erro-padrão & Coeficiente & Erro-padrão & Coeficiente & Erro-padrão & & \\
\hline 55 & Gasolina automotiva & $-1,297$ & 0,398 & $-1,527$ & 0,050 & 0,882 & 0,031 & $-0,364$ & 0,026 & 0,564 & 1598 \\
\hline 56 & Gasoálcool & $-6,083$ & 0,219 & $-1,231$ & 0,034 & 1,217 & 0,009 & $-0,116$ & 0,016 & 0,887 & 2656 \\
\hline 57 & Óleo combustivel & $-4,084$ & 0,231 & $-1,288$ & 0,032 & 1,229 & 0,021 & $-0,282$ & 0,015 & 0,673 & 2436 \\
\hline 58 & Óleo diesel & $-7,091$ & 0,242 & $-1,070$ & 0,031 & 1,260 & 0,017 & $-0,249$ & 0,014 & 0,741 & 2434 \\
\hline 59 & $\begin{array}{l}\text { Outros produtos do refino de } \\
\text { petróleo e coque }\end{array}$ & $-3,748$ & 0,303 & $-1,078$ & 0,035 & 0,925 & 0,029 & $-0,317$ & 0,016 & 0,363 & 3915 \\
\hline 60 & Álcool & $-4,004$ & 0,218 & $-0,959$ & 0,036 & 0,878 & 0,018 & $-0,177$ & 0,012 & 0,510 & 2778 \\
\hline 61 & Produtos químicos inorgânicos & $-3,479$ & 0,084 & $-1,676$ & 0,016 & 1,086 & 0,005 & $-0,316$ & 0,006 & 0,707 & 24708 \\
\hline 62 & Produtos químicos orgânicos & $-3,651$ & 0,158 & $-1,873$ & 0,029 & 1,062 & 0,006 & $-0,303$ & 0,012 & 0,602 & 21040 \\
\hline 63 & $\begin{array}{l}\text { Fabricação de resina e } \\
\text { elastômeros }\end{array}$ & $-0,697$ & 0,166 & $-2,199$ & 0,029 & 1,045 & 0,009 & $-0,501$ & 0,012 & 0,604 & 13441 \\
\hline 64 & Produtos farmacêuticos & $-0,197^{*}$ & 0,112 & $-1,891$ & 0,021 & 1,026 & 0,005 & $-0,525$ & 0,008 & 0,759 & 16810 \\
\hline 65 & Defensivos agrícolas & 0,555 & 0,138 & $-1,971$ & 0,025 & 1,152 & 0,008 & $-0,549$ & 0,010 & 0,787 & 8537 \\
\hline 66 & $\begin{array}{l}\text { Perfumaria, sabões e } \\
\text { artigos de limpeza }\end{array}$ & 1,787 & 0,080 & $-2,128$ & 0,015 & 0,985 & 0,004 & $-0,611$ & 0,006 & 0,790 & 23189 \\
\hline 67 & Tintas, vernizes, esmaltes e lacas & 1,123 & 0,104 & $-1,854$ & 0,019 & 1,003 & 0,006 & $-0,572$ & 0,007 & 0,754 & 15340 \\
\hline 68 & $\begin{array}{l}\text { Produtos e preparados } \\
\text { químicos diversos }\end{array}$ & 1,304 & 0,088 & $-1,946$ & 0,016 & 0,943 & 0,005 & $-0,554$ & 0,006 & 0,760 & 19726 \\
\hline 69 & Artigos de borracha & 0,180 & 0,087 & $-1,863$ & 0,017 & 0,914 & 0,005 & $-0,393$ & 0,006 & 0,675 & 23552 \\
\hline 70 & Artigos de plástico & $0,096 *$ & 0,080 & $-1,939$ & 0,015 & 0,929 & 0,004 & $-0,475$ & 0,006 & 0,769 & 24891 \\
\hline 71 & Cimento & $-0,421$ & 0,213 & $-1,279$ & 0,034 & 0,778 & 0,019 & $-0,358$ & 0,013 & 0,457 & 4517 \\
\hline 72 & $\begin{array}{l}\text { Outros produtos de } \\
\text { minerais não metálicos }\end{array}$ & 1,075 & 0,065 & $-2,256$ & 0,012 & 0,696 & 0,005 & $-0,156$ & 0,004 & 0,674 & 28903 \\
\hline 73 & Gusa e ferro-liga & $-11,227$ & 0,405 & $-0,234$ & 0,070 & 1,128 & 0,029 & $-0,134$ & 0,029 & 0,261 & 5003 \\
\hline 74 & $\begin{array}{l}\text { Semiacabacados, laminados } \\
\text { planos, longos e tubos de aço }\end{array}$ & $-7,672$ & 0,232 & $-0,833$ & 0,033 & 1,058 & 0,018 & $-0,231$ & 0,014 & 0,491 & 4690 \\
\hline 75 & $\begin{array}{l}\text { Produtos da metalurgia de } \\
\text { metais não ferrosos }\end{array}$ & 2,736 & 0,095 & $-2,382$ & 0,018 & 0,900 & 0,005 & $-0,554$ & 0,007 & 0,762 & 17843 \\
\hline 76 & Fundidos de aço & $-0,546$ & 0,107 & $-1,586$ & 0,020 & 0,920 & 0,006 & $-0,304$ & 0,008 & 0,635 & 20179 \\
\hline
\end{tabular}




\begin{tabular}{|c|c|c|c|c|c|c|c|c|c|c|c|}
\hline \multirow{2}{*}{\multicolumn{2}{|c|}{ Produtos }} & \multicolumn{2}{|l|}{ Constante } & \multicolumn{2}{|c|}{$\ln$ (Custos) } & \multicolumn{2}{|l|}{$\ln (P \mid B)$} & \multicolumn{2}{|c|}{ In(Densidade) } & \multirow{2}{*}{$\mathrm{R}^{\mathrm{R} 2}$} & \multirow[t]{2}{*}{ Amostra } \\
\hline & & Coeficiente & Erro-padrão & Coeficiente & Erro-padrão & Coeficiente & Erro-padrão & Coeficiente & Erro-padrão & & \\
\hline 77 & $\begin{array}{l}\text { Produtos de metal - exclusive } \\
\text { máquinas e equipamento }\end{array}$ & $-0,775$ & 0,087 & $-1,938$ & 0,016 & 0,926 & 0,005 & $-0,412$ & 0,006 & 0,690 & 28170 \\
\hline 78 & $\begin{array}{l}\text { Máquinas e equipamentos, } \\
\text { inclusive manutenção e reparos }\end{array}$ & $-2,011$ & 0,093 & $-1,790$ & 0,017 & 0,969 & 0,005 & $-0,396$ & 0,007 & 0,694 & 26818 \\
\hline 79 & Eletrodomésticos & $-1,372$ & 0,126 & $-1,575$ & 0,024 & 1,038 & 0,006 & $-0,395$ & 0,009 & 0,767 & 11677 \\
\hline 80 & $\begin{array}{l}\text { Máquinas para escritório } \\
\text { equipamentos de informát }\end{array}$ & 0,846 & 0,116 & $-2,167$ & 0,021 & 0,994 & 0,005 & $-0,323$ & 0,008 & 0,829 & 10184 \\
\hline 81 & $\begin{array}{l}\text { Máquinas, aparelhos e } \\
\text { material elétrico }\end{array}$ & $-1,560$ & 0,098 & $-1,663$ & 0,018 & 0,981 & 0,004 & $-0,461$ & 0,007 & 0,756 & 20694 \\
\hline 82 & $\begin{array}{l}\text { Material eletrônic } \\
\text { equipamentos de }\end{array}$ & $0,178 \%$ & 0,093 & $-2,093$ & 0,017 & 0,942 & 0,004 & $-0,317$ & 0,007 & 0,823 & 13844 \\
\hline 83 & $\begin{array}{l}\text { Aparelhos/i } \\
\text { hospitalar, r }\end{array}$ & $-0,333$ & 0,101 & $-1,693$ & 0,019 & 1,008 & 0,005 & $-0,486$ & 0,007 & 0,741 & 20135 \\
\hline 84 & $\begin{array}{l}\text { Automóveis, } \\
\text { camionetas e utilitár }\end{array}$ & $-7,049$ & 0,286 & $-1,018$ & 0,035 & 1,154 & 0,018 & $-0,327$ & 0,013 & 0,582 & 5371 \\
\hline 85 & Caminhões e ônibus & 0,312 & 0,402 & $-0,648$ & 0,058 & 1,526 & 0,029 & $-0,303$ & 0,023 & 0,748 & 1053 \\
\hline 86 & $\begin{array}{l}\text { Pecas e acessóric } \\
\text { automotores }\end{array}$ & $-1,242$ & 0,092 & $-1,735$ & 0,017 & 0,899 & 0,004 & $-0,423$ & 0,007 & 0,706 & 24117 \\
\hline 87 & $\begin{array}{l}\text { Outros eq } \\
\text { transport }\end{array}$ & 0,748 & 0,105 & $-2,172$ & 0,020 & 0,775 & 0,006 & $-0,218$ & 0,008 & 0,663 & 16241 \\
\hline 88 & $\begin{array}{l}\text { Móveis e produtos das } \\
\text { indústrias diversas }\end{array}$ & $-1,233$ & 0,085 & $-1,959$ & 0,016 & 0,922 & 0,005 & $-0,189$ & 0,006 & 0,654 & 28238 \\
\hline 89 & Sucatas recicladas & 3,510 & 0,087 & $-2,096$ & 0,017 & 0,843 & 0,006 & $-0,369$ & 0,006 & 0,669 & 21633 \\
\hline 90 & $\begin{array}{l}\text { Producão e distribuicão } \\
\text { eletricidade, gás, água, } \\
\text { limpeza urbana }\end{array}$ & 0,378 & 0,063 & $-2,336$ & 0,012 & 0,816 & 0,004 & $-0,310$ & 0,004 & 0,760 & 28628 \\
\hline 91 & Construc̣ão civil & $-0,784$ & 0,082 & $-2,356$ & 0,015 & 0,799 & 0,005 & $-0,382$ & 0,006 & 0,670 & 29107 \\
\hline 92 & Comércio & $-0,862$ & 0,086 & $-2,363$ & 0,014 & 0,573 & 0,006 & $-0,127$ & 0,005 & 0,552 & 29284 \\
\hline 93 & Transporte de carga & $-1,630$ & 0,105 & $-2,040$ & 0,019 & 0,930 & 0,006 & $-0,500$ & 0,007 & 0,596 & 28723 \\
\hline 94 & Transporte de passageiro & 0,424 & 0,083 & $-2,352$ & 0,015 & 0,852 & 0,005 & $-0,429$ & 0,006 & 0,691 & 28916 \\
\hline 95 & Correio & 1,082 & 0,085 & $-2,414$ & 0,016 & 0,616 & 0,006 & $-0,088$ & 0,006 & 0,525 & 29284 \\
\hline 96 & Serviços de informação & $-0,429$ & 0,089 & $-2,175$ & 0,016 & 0,964 & 0,005 & $-0,644$ & 0,006 & 0,709 & 28886 \\
\hline 97 & $\begin{array}{l}\text { Intermediacão financeira, seguros } \\
\text { e previdência complementar e } \\
\text { serviços relacionados }\end{array}$ & $-2,111$ & 0,093 & $-2,124$ & 0,016 & 0,965 & 0,006 & $-0,467$ & 0,006 & 0,629 & 29272 \\
\hline 98 & Atividades imobiliárias e aluguéis & $-0,699$ & 0,090 & $-1,942$ & 0,017 & 0,988 & 0,005 & $-0,726$ & 0,006 & 0,736 & 24955 \\
\hline
\end{tabular}




\begin{tabular}{|c|c|c|c|c|c|c|c|c|c|c|c|}
\hline \multirow{2}{*}{\multicolumn{2}{|c|}{ Produtos }} & \multicolumn{2}{|l|}{ Constante } & \multicolumn{2}{|l|}{ In(Custos) } & \multicolumn{2}{|l|}{$\ln (\mathrm{PIB})$} & \multicolumn{2}{|c|}{ In(Densidade) } & \multirow[b]{2}{*}{$\mathrm{R} 2$} & \multirow[t]{2}{*}{ Amonclusão } \\
\hline & & Coeficiente & Erro-padrão & Coeficiente & Erro-padrão & Coeficiente & Erro-padrão & Coeficiente & Erro-padrão & & \\
\hline 99 & Aluguel imputado & $-2,291$ & 0,106 & $-1,754$ & 0,019 & 1,005 & 0,006 & $-0,699$ & 0,007 & 0,672 & 23189 \\
\hline 100 & $\begin{array}{l}\text { Serviçcos de manutenção e } \\
\text { reparação }\end{array}$ & 0,763 & 0,080 & $-2,185$ & 0,015 & 0,950 & 0,005 & $-0,634$ & 0,006 & 0,733 & 27523 \\
\hline 101 & $\begin{array}{l}\text { Serviços de alojamento e } \\
\text { alimentação }\end{array}$ & $0,113^{*}$ & 0,085 & $-2,251$ & 0,016 & 0,928 & 0,005 & $-0,627$ & 0,006 & 0,700 & 29165 \\
\hline 102 & Serviços prestados às empresas & 0,517 & 0,087 & $-2,326$ & 0,016 & 0,995 & 0,004 & $-0,743$ & 0,006 & 0,767 & 29156 \\
\hline 103 & Educação mercantil & $-0,372$ & 0,080 & $-2,170$ & 0,015 & 0,791 & 0,005 & $-0,305$ & 0,006 & 0,635 & 29142 \\
\hline 104 & Saúde mercantil & $-1,743$ & 0,121 & $-1,778$ & 0,022 & 1,006 & 0,007 & $-0,716$ & 0,008 & 0,611 & 21057 \\
\hline 105 & Serviços prestados às famílias & 0,768 & 0,077 & $-2,290$ & 0,014 & 0,894 & 0,005 & $-0,549$ & 0,005 & 0,722 & 29046 \\
\hline 106 & Serviços associativos & $-1,365$ & 0,098 & $-2,075$ & 0,018 & 0,909 & 0,007 & $-0,254$ & 0,007 & 0,540 & 29277 \\
\hline 107 & Serviços domésticos & $-3,566$ & 0,099 & $-1,905$ & 0,018 & 0,842 & 0,009 & 0,172 & 0,007 & 0,423 & 28189 \\
\hline 108 & Educação pública & $-2,235$ & 0,095 & $-2,039$ & 0,017 & 0,902 & 0,006 & $-0,342$ & 0,007 & 0,593 & 29142 \\
\hline 109 & Saúde pública & $-2,266$ & 0,109 & $-1,972$ & 0,020 & 0,948 & 0,007 & $-0,398$ & 0,008 & 0,552 & 29181 \\
\hline 110 & $\begin{array}{l}\text { Serviço público e } \\
\text { șeguriḍade șoçiạl }\end{array}$ & $-1,628$ & 0,090 & $-2,382$ & 0,015 & 0,585 & 0,007 & 0,042 & 0,006 & 0,498 & 29284 \\
\hline
\end{tabular}

Fonte: Resultados obtidos utilizando o programa Stata 10.0

Observação: Todos os coeficientes são significantes ao nível de 1\%, com exceção da sinalização que se segue: i) * indica coeficientes não significativos a 10\%; ii) ${ }^{* *}$ indica coeficientes significativos a $10 \%$ e iii) ${ }^{\star * *}$ indica coeficientes significativos a $5 \%$.

Por fim, pode ser calculado um coeficiente médio igual a -2,133 para o setor de serviços, sendo os principais destaques os produtos Correio (-2,414), Serviço público e seguridade social $(-2,382)$ e Comércio $(-2,363)$. A estimativa média mostrou-se mais elástica do que a apresentada em Haddad (2004) (-0,878). Essa análise para o setor de serviços tem grande importância prática, na medida em que a quase inexistência de estimativas de elasticidades na literatura para esse setor faz com que tais valores sejam muitas vezes fixados de forma ad hoc na calibragem de modelos EGC. Finalmente, vale mencionar que a forma de adoção das elasticidades calculadas neste estudo pode ser utilizada para calibragem de modelos de EGC, cabendo ao pesquisador
Tabela 2_Comparação das estimativas médias das elasticidades do comércio regional dos setores

\begin{tabular}{l|r|r|r|r}
\hline Estudo & Agropecuária & Extrativo & Indústria & Serviços \\
\hline Tooze (1976)* & & & $-1,125$ & \\
\hline Bilgic et al. (2002) & $-1,477$ & $-2,151$ & $-0,840$ & \\
\hline Haddad (2004) & $-1,720$ & & $-2,079$ & $-0,878$ \\
\hline Faria (2009) & $-3,887$ & $-1,557$ & $-0,862$ & \\
\hline Turner et al. (2012) & $-0,645$ & $-0,963$ & $-1,057$ & \\
\hline Presente estudo & $-1,894$ & $-1,177$ & $-1,820$ & $-2,133$ \\
\hline
\end{tabular}

Nota: ${ }^{\star}$ Resultado reportado sob a hipótese de retornos constantes de escala. 
encontrar a melhor configuração para aplicação de caso específico (e.g. nível de agregação setorial e/ou espacial).

\section{5_Considerações finais}

O nível de comércio entre regiões é um importante indicativo de algumas relações de dependência de bens e serviços que podem existir em uma economia integrada. Regiões, por exemplo, que possuem população distribuída de forma mais esparsa no território tendem a despender quantia maior de sua produção ao consumo próprio, ao passo que regiões com maior escala de mercado, no que diz respeito ao potencial de consumo e oferta de insumos a produção, têm maior disposição à realização de comércio. Essas e outras características podem indicar como o comércio pode se configurar no espaço econômico, sendo possível também identificar os principais fluxos e os bens transacionados. $\mathrm{O}$ presente estudo não focou diretamente na forma com que tal dependência ocorre com relação ao comércio dentro do Brasil, mas sim na obtenção do grau de sensibilidade dos produtos ao comércio inter-regional.

Dessa forma, foram obtidas estimativas de elasticidades de comércio regional entre as 558 microrregiões do Brasil para os 110 produtos classificados de acordo com a nomenclatura do Novo Sistema de Contas Nacionais do IBGE. Para isso, foi utilizado amplo banco de dados construído com base em informações específicas da economia brasileira, seguindo algumas etapas técnicas de implementação e critérios rigorosos de validação dos dados. Esta parte do trabalho representou um ponto importante, dado o fato de que a geração das informações sobre o fluxo de comércio e o custo de transporte inter-regional não é trivial. A forma de modelagem foi realizada similarmente ao procedimento adotado por Bilgic et al. (2002), que, juntamente com o trabalho de Armington (1969), foram as principais referências para a obtenção da equação final a ser estimada. O trabalho fundamenta-se na hipótese de Armington acerca do comércio regional.

Assim, pressupõe-se que os produtos sejam substitutos imperfeitos do ponto de vista dos compradores regionais. $\mathrm{O}$ grau de substituição de determinado produto, por sua vez, está relacionado com o custo de transporte inter-regional, que afeta os seus preços relativos em determinado mercado local. Dessa forma, os custos de transferência (custos de transação dos produtos entre regiões) funcionam como uma medida de impedância ao fluxo de comércio. Valendo-se da hipótese de Armington do comércio regional e do fato de que os custos de transporte afetam os preços relativos dos produtos, é testa-se a hipótese subjacente de uma relação negativa entre alterações nos preços relativos e a penetração de produtos de origens diversas em um mercado específico. Como pode ser constatado pelos resultados encontrados, observou-se tal relação nos mercados dos vários produtos contemplados.

Um dos focos do trabalho, além da estimação das elasticidades de substituição no comércio para o Brasil, reside na documentação de procedimentos para se estimar os fluxos de comércio inter-regional, visando subsidiar esforços futuros nessa direção. No processo de calibragem de modelos inter-regionais de grande escala (e.g. modelos EGC), tais informações tornam-se fundamentais para melhor se captarem as relações de interdependência espacial em um contexto sistêmico.

\footnotetext{
Notas

${ }^{1}$ Foram utilizadas rotinas em MATLAB para a implementação do procedimento de cálculo dos fluxos de comércio inter-regional.

${ }^{2}$ Informações como a adoção da hipótese de comportamento maximizador dos compradores,
}

\author{
hipóteses adicionais quanto \\ à especificação das funções \\ definidas até este ponto e das \\ propriedades de $\mathrm{P}_{i}$ e $\mathrm{X}_{i}$ podem ser \\ encontradas em Armington (1969). \\ ${ }^{3}$ Ver Wooldridge (2002, cap. 7) \\ para mais detalhes.
}




\author{
ARMINGTON, P. A. A Theory \\ of Demand for Products \\ Distinguished by Place of \\ Production. International \\ Monetary Fund Staff Papers, v. \\ 16, p. 159-178, 1969.
}

BILGIC, A.; KING, S.; LUSBY, A.; SCHREINER, D. F. Estimates of U.S. regional commodity trade elasticities. Journal of Regional Analysis and Policy, v. 32, n. 2, p. 79-98, 2002.

BLONIGEN, B. A.; WILSON, W. W. Explaining Armington: What determines substitutability between home and foreign goods? Canadian Journal of Economics, v. 32, p. 1121, 1999.

DIXON, P. B.; PARMENTER, B. R.; POWELL, A. A.; WILCOXEN, P. J. Notes and problem in applied general equilibrium economics. North-Holland: Amsterdam, 1992.

DIXON, P. B.; PARMENTER, B. R.; POWELL, A. A.; WILCOXEN, P. J. ; RIMMER, M. T. Disaggregation of results from a detailed general equilibrium model of the US to the State level. Working Paper, Centre of Policy Studies, Monash University, 2004.
FARIA, W. R. Efeitos regionais de investimentos em infraestrutura de transporte rodoviário. $143 \mathrm{f}$. Dissertação (Mestrado em Economia) Universidade Federal de Minas Gerais, Belo Horizonte, Minas Gerais, 2009.

GALLAWAY, M. P.; MCDANIEL, C. A.; RIVERA, S. A. Short-run and long-run industry-level estimates of U.S. Armington elasticities. North American Journal of Economics and Finance, v. 14, p. 49-68, 2003. HADDAD, E. A. Retornos crescentes, custos de transporte e crescimento regional. 2004. $207 \mathrm{f}$. Tese (Livre-docência em Economia) - Instituto de Pesquisas Econômicas, Universidade de São Paulo, São Paulo, 2004.

MAGALHÃES, A. S. O comércio por vias internas e seu papel sobre crescimento e desigualdade regional no Brasil. 134 f. Dissertação (Mestrado em Economia) Universidade Federal de Minas Gerais, Belo Horizonte, Minas Gerais, 2009.

PARTRIDGE, M. D.; RICKMAN, D. S. Regional computable general equilibrium modeling: A survey and critical appraisal. International Regional Science Review, v. 21, n. 3, p. 205-248, 1998.
REINERT, K. A.; ROLAND-HOLST, D. W. Armington elasticities for United States manufacturing sectors. Journal of Policy Modeling, v. 14, p. 631-639, 1992.

SHIELLS, C. R.; STERN, R. M.; DEARDORFF, A. V. Estimates of the elasticities of substitution between imports and home goods for the United States. Weltwirtschaftliches-Archiv, 122, p. 497-519, 1986.

SHIELLS, C. R.; STERN, R. M.; DEARDORFF, A. V. ; REINERT, K. A. Armington models and terms-of-trade effects: Some econometric evidence for North America. Canadian Journal of Economics, v. 26, p. 299-316, 1993.

TOOZE, M. J. Regional elasticities of substitution in the United Kingdom in 1968. Urban Studies, v. 13, p. 35-44, 1976.

TURNER, K.; HA, S. J.; HEWINGS, G. J. D.; McGREGOR, P.; SWALES, K. Econometric estimation of Armington import elasticities for a Regional CGE Model of the Illinois Economy. Economic Systems Research, v. 24, n. 1, p. 1-20, 2012.

WOOLDRIDGE, J. M.

Econometric analysis of cross section and Panel Data. England: Mit Press, 2002.
E-mail de contato dos autores:
weslem.faria@ufjf.edu.br

ehaddad@usp.br

Artigo recebido em abril de 2012 aprovado em outubro de 2012 
Anexo

Figura A.1_Correlação entre Rendimento do Trabalho da PNAD e Despesa Familiar da POF

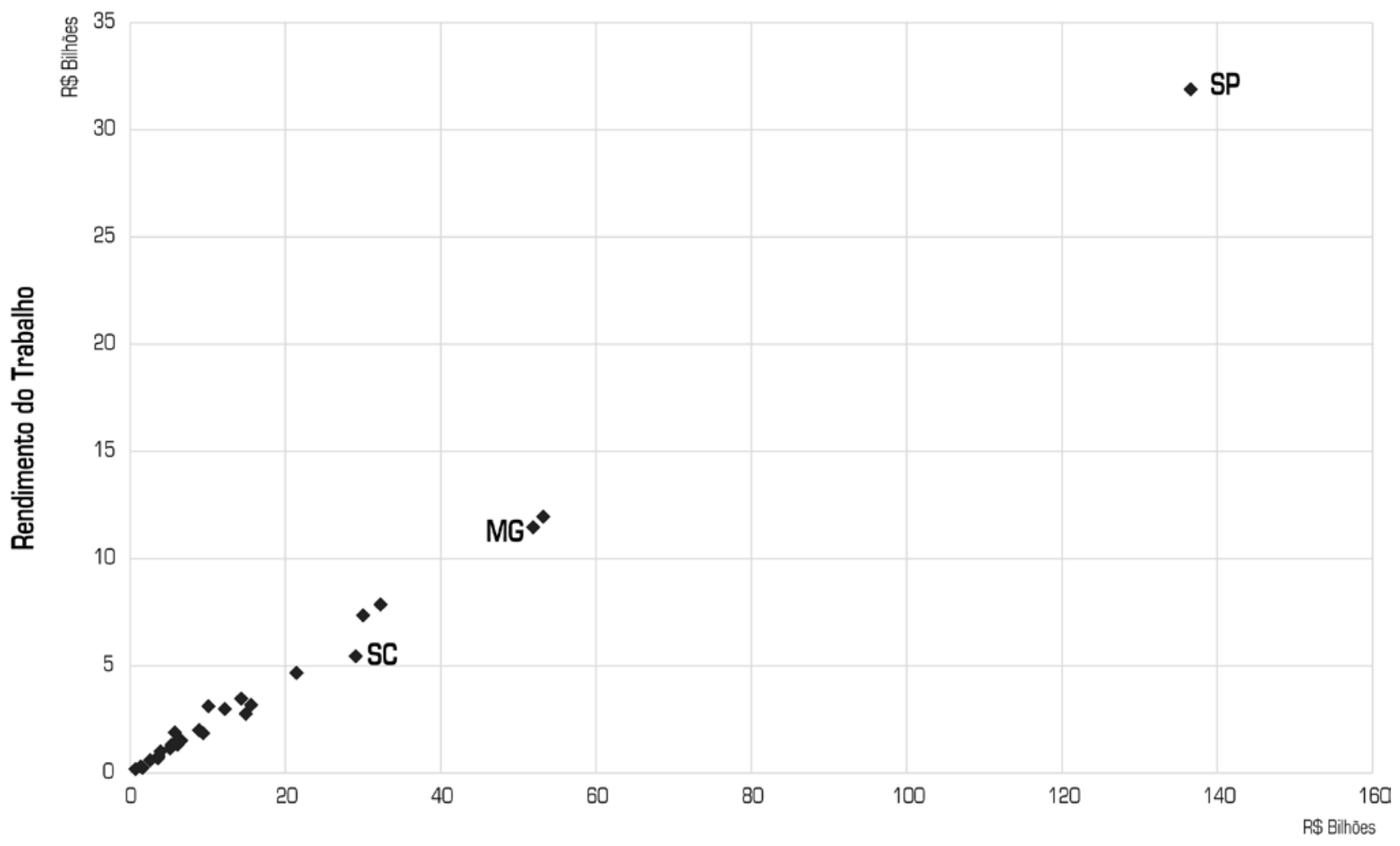

Despesa Familiar 
Tabela A.1_Produtos contemplados pela Matriz O-D

\section{Produtos}

\begin{tabular}{|c|c|c|c|}
\hline 1 & Arroz em casca & 29 & Óleo de soja em bruto e tortas, bagaços e farelo de soja \\
\hline 2 & Milho em grão & 31 & Óleo de soja refinado \\
\hline 3 & Trigo em grão e outros cereais & 34 & Arroz beneficiado e produtos derivados \\
\hline 4 & Cana-de-açúcar & 35 & Farinha de trigo e derivados \\
\hline 5 & Soja em grão & 36 & Farinha de mandioca e outros \\
\hline 6 & Outros produtos e serviços da lavoura & 37 & Óleos de milho, amidos e féculas vegetais e rações \\
\hline 7 & Mandioca & 38 & Produtos das usinas e do refino de açúcar \\
\hline 8 & Fumo em folha & 39 & Café torrado e moído \\
\hline 9 & Algodão herbáceo & 40 & Café solúvel \\
\hline 10 & Frutas cítricas & 43 & Produtos do fumo \\
\hline 11 & Café em grão & 51 & Celulose e outras pastas para fabricação de papel \\
\hline 12 & Produtos da exploração florestal e da silvicultura & 54 & Gás liquefeito de petróleo \\
\hline 13 & Bovinos e outros animais vivos & 55 & Gasolina automotiva \\
\hline 14 & Leite de vaca e de outros animais & 56 & Gasoálcool \\
\hline 15 & Suínos vivos & 57 & Óleo combustível \\
\hline 16 & Aves vivas & 58 & Óleo diesel \\
\hline 17 & Ovos de galinha e de outras aves & 59 & Outros produtos do refino de petróleo e coque \\
\hline 18 & Pesca e aquicultura & 60 & Álcool \\
\hline 19 & Petróleo e gás natural & 61 & Produtos químicos inorgânicos \\
\hline 20 & Minério de ferro & 62 & Produtos químicos orgânicos \\
\hline 21 & Carvão mineral & 63 & Fabricação de resina e elastômeros \\
\hline 22 & Minerais metálicos não-ferrosos & 71 & Cimento \\
\hline 23 & Minerais não-metálicos & 73 & Gusa e ferro-ligas \\
\hline 24 & Abate e preparação de produtos de carne & 74 & Semi-acabacados, laminados planos, longos e tubos de aço \\
\hline 25 & Carne de suíno fresca, refrigerada ou congelada & 84 & Automóveis, camionetas e utilitários \\
\hline 26 & Carne de aves fresca, refrigerada ou congelada & 85 & Caminhões e ônibus \\
\hline
\end{tabular}


Tabela A.2_Tabela de conversão Grupos CNAE 2.0 para 110 produtos das Contas Nacionais

\begin{tabular}{|c|c|c|c|}
\hline $\begin{array}{l}\text { Produtos - } \\
\text { Contas Nacionais }\end{array}$ & Grupos - CNAE 2.0 & $\begin{array}{l}\text { Produtos - } \\
\text { Contas Nacionais }\end{array}$ & Grupos - CNAE 2.0 \\
\hline 27 & 10,2 & 80 & 26,2 \\
\hline 28 & 10,3 & 81 & 27.1; 27.2; 27.3; 27.4; 27.9 \\
\hline 30 & 10,4 & 82 & 26.1; 26.6; 26.4 \\
\hline 32 & 10,5 & 83 & $26.6 ; 32.5$ \\
\hline 33 & 10,5 & 86 & 29.3; 29.4; 29.5 \\
\hline 41 & 10,9 & 87 & $\begin{array}{r}30.1 ; 30.3 ; 30.4 ; 30.5 ; \\
30.9\end{array}$ \\
\hline 42 & $11.1 ; 11.2$ & 88 & 31 \\
\hline 44 & 13,1 & $89 \%$ & $46.87-7$ \\
\hline 45 & 13,2 & 90 & $\begin{array}{r}\text { 35.1; 35.2; 35.3. 36.0; } \\
\text { 37.0; 38.1; 38.2; 38.3; 39.0 }\end{array}$ \\
\hline 46 & 13,3 & 91 & $\begin{array}{r}41.1 ; 41.2 ; 42.1 ; 42.9 ; 43.1 ; \\
43.2 ; 43.3 ; 43.9\end{array}$ \\
\hline 47 & $\begin{array}{r}13.4 ; 13.5 ; 14.1 ; \\
14.2\end{array}$ & 92 & $\begin{array}{r}45.1 ; 45.3 ; 45.4 ; 46 ; 1 ; \\
46.2 ; 46.3 ; 46.4 ; 46.5 ; \\
46.6 ; 46.7 ; 46.8 ; 46.9 \\
47.1 ; 47.2 ; 47.3 ; 47.4 ; 47.5 ; \\
47.6 ; 47.7 ; 47.8 ; 47.9\end{array}$ \\
\hline 48 & $15.1 ; 15.2$ & 93 & $\begin{array}{l}49.1 ; 49.3 ; 49.4 ; 50.1 ; \\
50.2 ; 50.3 ; 50.9 ; 51.2\end{array}$ \\
\hline 49 & $15.3 ; 15.4$ & 94 & 49.2; 49.5; 51.1; 51.3 \\
\hline 50 & $16.1 ; 16.2$ & 95 & 53.1; 53.2 \\
\hline 52 & $17.2 ; 17.3 ; 17.4$ & 96 & $\begin{array}{r}\text { 58.1; 58.2; 59.1; 59.2; 60.1; } \\
\text { 60.2; 61.1; 61.2; 61.3; 61.4; } \\
61.9 ; 62.0 ; 63.1 ; 63.9\end{array}$ \\
\hline 53 & 18.1; 18.2; 18.3 & 97 & $\begin{array}{r}\text { 64.1; 64.2; 64.3; 64.4; } \\
64.5 ; 64.6 ; 64.7 ; 64.9 ; \\
65.1 ; 65.2 ; 65.3 ; 66.1 ; \\
66.2 ; 66.3\end{array}$ \\
\hline 64 & 21.1; 21.2 & 98 & $68.1 ; 68.2$ \\
\hline 65 & 20,5 & $99 \%$ & 68.21-8 \\
\hline
\end{tabular}




\begin{tabular}{|c|c|c|c|}
\hline $\begin{array}{l}\text { Produtos - } \\
\text { Contas Nacionais }\end{array}$ & Grupos - CNAE 2.0 & $\begin{array}{l}\text { Produtos - } \\
\text { Contas Nacionais }\end{array}$ & Grupos - CNAE 2.0 \\
\hline 66 & 20,6 & 100 & $95.1 ; 95.2$ \\
\hline 67 & 20,7 & 101 & $55.1 ; 55.9 ; 56.1 ; 56.2$ \\
\hline 68 & 20,9 & 102 & 82.1; 82.2; 82.3; 82.9 \\
\hline 69 & 22,1 & 103 & $\begin{array}{r}80.1 ; 80.2 ; 80.3 ; 80.4 ; \\
80.5 ; 80.9\end{array}$ \\
\hline 70 & 22,2 & 104 & 65,5 \\
\hline 72 & 23.3; 23.4; 23.9 & 105 & 95.1; 95.2; 96.0; 97.0 \\
\hline 75 & 24,4 & 106 & $94.1 ; 94.2 ; 94.3 ; 94.9$ \\
\hline 76 & 24,5 & 107 & 97 \\
\hline 77 & $\begin{array}{l}\text { 25.1, 25.2; 25.3; } \\
25.4 ; 25.5 ; 25.9\end{array}$ & 108 & $\begin{array}{r}80.1 ; 80.2 ; 80.3 ; 80.4 \\
80.5 ; 80.9\end{array}$ \\
\hline 78 & $\begin{array}{r}\text { 28.1; 28.2; 28.3; } \\
\text { 28.4; 28.5; 28.6; } \\
\text { 33.1; 33.2 }\end{array}$ & 109 & $\begin{array}{r}86.1 ; 86.2 ; 86.3 ; 86.4 ; \\
86.5 ; 86.9 ; 87.1 ; 87.2 ; 87.3 ; \\
88.0\end{array}$ \\
\hline 79 & 27,5 & 110 & 84.1; 84.2; 84.3 \\
\hline
\end{tabular}

As observações em $\left.{ }^{*}\right)$ e ${ }^{* *}$ ) relativas aos produtos 89 e 99 identificam, respectivamente, a utilização para esses produtos da divisão de Classe da CNAE, mais detalhada do que a divisão de Grupo. Decidiu-se por isso, já que fornece informação mais refinada e adequada acerca dos produtos em questão. 